\title{
Recent Advances in Metal-Organic Vapor Phase Epitaxy
}

THOMAS F. KUECH, MEMBER, IEEE

Invited Paper

The recent progress in the development and application of metalorganic vapor phase epitaxy (MOVPE) is reviewed. Advances in this technique have allowed the formation of new and unique materials and structures. Wide-bandgap materials of both III-V and II-VI semiconductors are examples of new materials which can have an impact on optical and electronic device structures. The basic studies of the underlying chemistry and fluid flow behavior in MOVPE reactors have brought improvements in the control of material properties and the uniformity of growth. New growth precursors can yield both selective area growth and improved material purity. Improved reproducibility of the MOVPE growth product using growth monitors, for the real-time determination of film thickness and composition, results in a greater acceptance of the MOVPE technique in the manufacturing environment.

\section{INTRODUCTION}

Metal-organic vapor phase epitaxy (MOVPE) has developed over the past 15 years into one of the premier techniques for the epitaxial growth of thin layer structures. This technique has been applied to virtually all advanced device structures utilizing most of the principal compound semiconductor materials. The MOVPE technique has made strong contributions to the research laboratory, where a wide variety of device structures can be rapidly formed within the same growth system. The versatility of the MOVPE technique and MOVPE growth systems is unparalleled. The MOVPE technique was initially developed in response to the lack of availability of large-area high-purity $\mathrm{GaAs}$ substrates. The MOVPE-based growth of GaAs and other materials on large-diameter sapphire wafers was investigated as a replacement for single-crystal substrates. In a series of papers, Manasevit and coworkers demonstrated the wide range of materials which could be grown by MOVPE [1]. This range of material growth possibilities was attributed to the large number of metal-organic precursors that were available for use and the chemical similarity between those precursors. This chemical similarity allows

Manuscript received February 1, 1992; revised July 2, 1992. This work was supported in part by the National Science Foundation (DMR-9106633) and the Naval Research Laboratory (NC0014-92-K-2004).

The author is with the Department of Chemical Engineering, University of Wisconsin, Madison, WI 53705

IEEE Log Number 9205057. for the easy exchange of these precursors without a large change in growth conditions. As the bulk crystal growth technology improved, the application of MOVPE to the epitaxial growth of GaAs and related materials on existing single substrates quickly moved to the forefront of research activity.

It was quickly recognized that MOVPE could overcome several of the difficulties in the then principal epitaxial technology, vapor phase epitaxy (VPE). The halidebased VPE growth was well adapted to the formation of materials within the In and $\mathrm{Ga}$ based compound semiconductor systems. $\mathrm{Al}_{x} \mathrm{Ga}_{1-x}$ As containing devices were difficult to form by VPE; therefore liquid phase epitaxy (LPE) remained the epitaxial technology of choice for these materials. A principal drawback of LPE was the difficulty in achieving thin layer structures with abrupt interfaces. The materials studies of Stringfellow [2] and Dupuis and Dapkus [3], as well as other researchers, indicated that the MOVPE technique could be used to make high-purity $\mathrm{Al}_{x} \mathrm{Ga}_{1-x}$ As suitable for light-emitting structures. The demonstration of low-threshold lasers using $\mathrm{Al}_{x} \mathrm{Ga}_{1-x} \mathrm{As} / \mathrm{GaAs}$ materials placed MOVPE as a strong competitor for the future development of solid-state lasers. Since these early landmark studies, the MOVPE technique has been developed to include most semiconductor material systems and device structures.

The application and research into MOVPE materials and devices have continued to focus on the formation of devices which are dominated by minority carrier properties. Lasers, solar cells, photodetectors, and light-emitting diodes are principal research and commercial application areas. The growth of long-wavelength laser materials, based on the $\operatorname{In}_{x} \mathrm{Ga}_{1-x} \mathrm{P}_{y} \mathrm{As}_{1-y}$ system of materials, is principally within the domain of MOVPE. The underlying reasons for the dominance of MOVPE over such a wide range of materials systems is clear. On a materials level, the MOVPE-based $\mathrm{Al}_{x} \mathrm{Ga}_{1-x}$ As appears to generally possess better luminescence properties (minority carrier lifetime, luminescence efficiency) than its molecular beam epitaxy (MBE) counterparts. Both higher growth temperatures and 
the presence of reactive chemical species near or on the growth surface, such as $\mathrm{AsH}_{x}$, may aid in reducing the incorporation of oxygen into the growing crystal [4]. Oxygen has been widely considered to be one of the principal deep-level impurities in these materials. The formation of phosphorus-bearing materials, which are lattice matched to an InP substrate, is central to long-wavelength light emitters and detectors. The $\operatorname{In}_{x} \mathrm{Ga}_{1-x} \mathrm{P}_{y} \mathrm{As}_{1-y}$ materials systems require control over the relative ratio of both the cation and anion species within the alloy, as well as the growth rate [5]. The high vapor pressure of $P$ presents difficulties in the MBE formation of these materials, particularly from elemental or compound sources. The development of the chemical beam epitaxy (CBE) or metal-organic MBE (MOMBE) growth systems has started to address some of these difficulties [6]. The handling of $P$ compounds in the gas phase environment of MOVPE is a direct extension from the developed technology applied to the growth of the As-bearing materials. The wide availability of $P$ sources and the ease of development of multinary materials have pushed MOVPE to the forefront of device development within this materials system.

Commercialization of the technique has begun in several application areas. The commercial uses of MOVPE, however, have been limited to a few key applications, while remaining a mainstay within the material science and device development laboratory. The primary uses of MOVPE are in the production of solar cells, infrared detectors (night vision), and lasers. This latter device area will continue to expand as the commercial applications for solid-state lasers develop. These applications are well suited to the MOVPE growth technique with the range of growth uniformity in doping, thickness, and composition currently achievable to within a few percent. Solar cell and night vision applications have relaxed constraints on the acceptable doping and thickness uniformity. Solidstate lasers and other light emitters also possess relaxed constraints on the doping uniformity and, in many structures, the thickness uniformity. Electronic devices, such as field effect transistors (FET's) and other charge control devices, require a high degree of uniformity over the thickness-doping product. This is particularly true for integrated circuit applications within compound semiconductor systems. The lower voltage logic swings in these devices constrain the allowed variation in the growth uniformity and reproducibility to less than 1\%-2\%. MOVPE growth, as with most semiconductor processing and growth systems, is not controlled through active monitoring and control of the growth product or ambient. The achievement of such a high degree of control over the wafer properties is therefore the result of a tight regimen of materials characterization and system recalibration. There have been, however, several efforts toward the application of MOVPE to these devices which have demonstrated that MOVPE digital device structures are feasible in a manufacturing environment [7], [8]. The development of new "real-time" process monitors and control methodologies applicable to the MOVPE growth process is an active area of research and development. Both new MOVPE reactor designs and such new control procedures will widen the range of manufacturing applications for the MOVPE growth process.

The field of MOVPE continues to evolve in the development of new materials, in our basic understanding of the underlying growth chemistry and fluid thermal growth environment, and in the growth of unique structures. The recent advances within these three areas are described and discussed within this paper. The direction and application of MOVPE to both conventional and novel optical and electronic device structures are outlined, and, finally, the technological directions within these application areas are discussed.

\section{BASIC GROWTH ChEMISTRY AND GROWTH SySTEMS}

The choices of reactor geometry, growth chemistry, and growth conditions are the chief determinants of the materials and structural properties of the growing film. The historical development of the MOVPE field has relied principally on empirical determination and engineering insight in the development of new growth systems. There have been recent advances in all these areas which represent a growing measure of understanding and control over the growth system. Several of the principal advances in each of these areas will be discussed as representative of the current work.

\section{A. Reactor Design and Modeling}

The underlying growth chemistry within the MOVPE growth reactor intimately interacts with the thermal-fluid environment. The resulting gas phase and surface chemistry determines the growth uniformity, materials composition, and impurity incorporation. Research has largely focused on determining the relationship between the reactor geometry and the fluid behavior. These are largely numerical studies ranging from supercomputer-based studies to those utilizing simplifying assumptions which would enable the solution on a PC-based or workstation computer. The use of realistic boundary conditions and reactor geometries involves a much larger computing base. A chief feature of most of these studies is the separation of the mass transport and gas phase chemistry from the solution of the fluid-flow and thermal transport equations [9]. The reactants within the MOVPE reactor are very dilute with the result that the variations in the gas phase environment caused by the growth induced changes in the gas phase composition do not lead to changes in the flow behavior. The notable exception to this simplifying assumption is found in the modeling of the growth of $\mathrm{Hg}_{x} \mathrm{Cd}_{1-x} \mathrm{Te}$. While the mole fraction of the constituents, principally $\mathrm{Hg}$, is low, the density difference between $\mathrm{Hg}$ and the $\mathrm{H}_{2}$ carrier gas results in a strong potential coupling between the flow and the mass transport [10].

The solution of the nonlinear Navier-Stokes equations describing the thermal and fluid flow behavior within these MOVPE systems has been the object of increasing interest within the electronic materials and chemical engineering fields. The fluid behavior within the system can 
be characterized by forced and thermal convection, and in special cases by density driven or solutal convection [10]. The details of these flow characteristics principally affect the growth uniformity. Simple reactor geometries have been the most commonly modeled systems. Onedimensional similarity solutions [11] and two-dimensional models can reveal general operating conditions favorable to the establishment of stable controlled fluid flow within the reactor [12]. More aggressive studies have included a fully three-dimensional solution which incorporates realistic radiative thermal boundary conditions and typically requires a supercomputer for their timely solution [13], [14]. The outcomes of these studies are the velocity and temperature fields within the reactor, which can then be used in modeling the mass transport behavior of the growth reactants which governs the growth rate.

The development of a chemically based model of the MOVPE growth environment capable of predicting growth rate, alloy uniformity, and the doping and unintentional impurity incorporation into the growing films is at the forefront of numerical modeling efforts [15]. Predicting the alloy composition and overall growth rate is the easier of the two general classes of problems since it involves primarily major gas phase constituents. The growth rate and uniformity in the two- and three-dimensional models are generally obtained by using the assumptions of a mass transport limited growth rate. This simplifying assumption has been remarkably successful in predicting the growth rate uniformity. The fast reaction rates of the metal-organic precursors have simplified the formation of alloy semiconductors in practice and in theory. The development of a more detailed model of the additional chemistry related influences in the reactor, such as doping and impurity incorporation, as shown in Fig. 1, is limited by our knowledge of the detailed gas phase and surface chemistry and the availability of computing power. The large number of possible reactions requires the use of many assumptions concerning the nature and importance of various surface reactions. The most studied of these systems has been the growth of GaAs from $\left(\mathrm{CH}_{3}\right)_{3} \mathrm{Ga}$ and $\mathrm{AsH}_{3}$ [12], [13], [15]. The inclusion of surface specific reactions relying on the detailed knowledge of the nature and number of surface sites, their structural configuration, and the range of intermediate chemical forms on the surface has left these studies as demonstrations of the possible utility of such large numerical simulations once the appropriate chemical data are available [11], [16]. These large numerical studies have been met, however, by some skepticism within the experimentally oriented research community due to the uncertainty in and the number of reaction parameters. These models, once fully developed and verified, would provide a viable means by which to develop new processes and reactor designs without the high cost of a hardware oriented development process.

\section{B. New Growth Chemistries}

The development of new growth chemistries for materials deposition and dopant incorporation is an exciting area

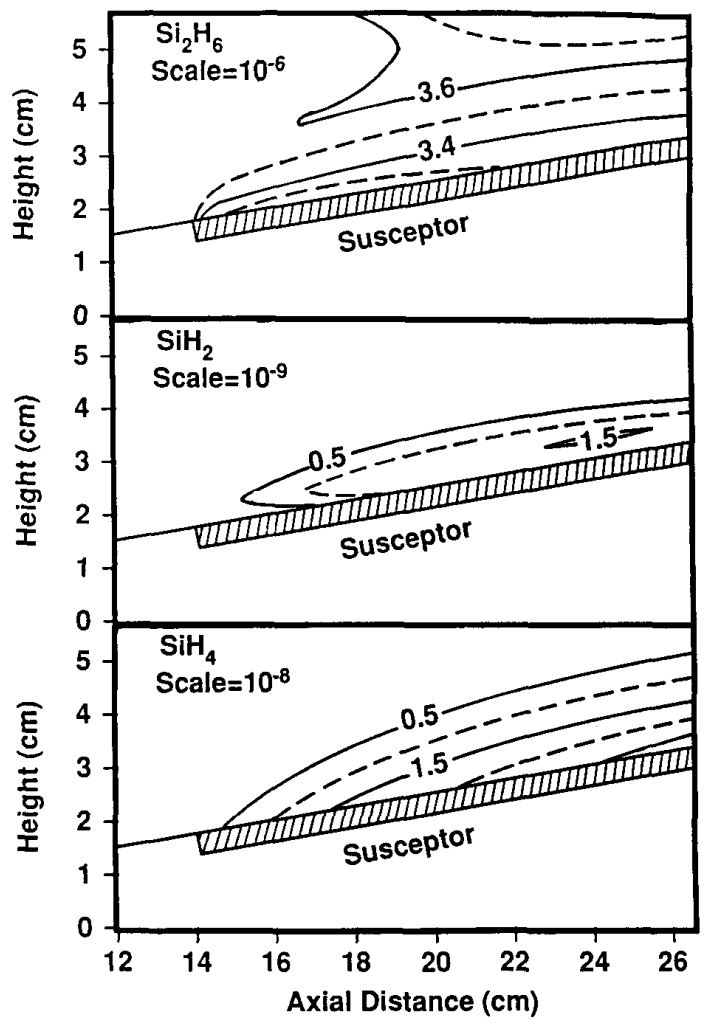

Fig. 1 The numerical modeling of a MOVPE reactor can include the gas phase and surface reaction kinetics of both the growth reaction and doping reactions. In this figure, the gas phase mole fractions of intermediates relevant to the Si doping of $\mathrm{GaAs}$ from $\mathrm{Si}_{2} \mathrm{H}_{6}$ are shown [15]. These data have been used to predict both doping and growth uniformity.

of current research. The recent developments in these areas have focused on the replacement of the group $\mathrm{V}$ sources of $\mathrm{AsH}_{3}$ and $\mathrm{PH}_{3}$ by less hazardous liquid based sources [17]-[22]. Additionally, the research on group III and II sources has been related to the improvement in the incorporation of impurities, principally carbon, and increased source stability. In most cases, the advances in the growth chemistry have targeted specific materials or growth related properties which are directly affected by the change in precursors. Any chemical precursor must fulfill several basic requirements in order to be viable in the MOVPE growth environment:

1) the source must have a convenient vapor pressure for ease of gas phase transport;

2) the decomposition pathways and temperatures must be suitable, providing for a usable growth rate at the growth temperatures of interest;

3) the source must decompose cleanly to the growth product;

4) the decomposition must proceed without the incorporation of ancillary impurities from the precursor itself;

5) the source must be capable of efficient and convenient purification. 
Given this extensive list of requirements for prospective precursors, the development of new precursors has been slow and generally limited to variations on the existing source molecules, through ligand variations, e.g. the exchange of methyl for ethyl groups as in $\left(\mathrm{CH}_{3}\right)_{3} \mathrm{Ga}$ versus $\left(\mathrm{C}_{2} \mathrm{H}_{5}\right)_{3} \mathrm{Ga}$.

The development of replacements for the group $\mathrm{V}$ hydrides for growth of $\mathbf{P}$ and As-based materials has been an ongoing collaboration between commercial concerns and the research community. It represents one of the success stories of such interactions. The design of these new sources was initially aimed at the reduction in both the toxicity and hazard associated with high-pressure sources, $\mathrm{PH}_{3}$ and $\mathrm{AsH}_{3}$ [20]. The hazard associated with these highpressure gases is related to the extent and rapidity with which these gases can spread when an uncontained release occurs. Liquid sources, such as organo-arsenic compounds, are less hazardous since a spill or other release is limited by the evaporation of the liquid source, which can be more efficiently contained. There have been several major precursors developed by chemical concerns which have been extensively developed and studied: tertiary butyl arsine $\left(\left(\mathrm{C}_{4} \mathrm{H}_{9}\right) \mathrm{AsH}_{2}\right)$ [18], tertiary butyl phosphine $\left(\left(\mathrm{C}_{4} \mathrm{H}_{9}\right) \mathrm{PH}_{2}\right)$ [18], and monoethyl arsine $\left(\mathrm{C}_{2} \mathrm{H}_{5} \mathrm{AsH}_{2}\right)$ [23]. These particular compounds are liquid at room temperature with an adequate vapor pressure for their use in MOVPE applications. The chemical function of these sources extends beyond the supply of a sufficient partial pressure of As or $P$ above the growth surface for both incorporation into the growing film and stabilization of the growth front. Common to both $\left(\mathrm{C}_{4} \mathrm{H}_{9}\right) \mathrm{AsH}_{2}$ and $\mathrm{C}_{2} \mathrm{H}_{5} \mathrm{AsH}_{2}$ is the presence of one or more $\mathrm{H}$ atoms bonded to the As atom. The hydrogen which is contained within these compounds, as well as in $\mathrm{AsH}_{3}$, plays a central role in the incorporation of carbon into the growing film when used in conjunction with the methyl-based group III precursors. The bimolecular reaction between this hydrogen and the methyl radicals [24] results in the formation of methane, which is basically inert within this growth environment [25]. Any replacement for arsine and phosphine must also perform this same function in order to provide low carbon contamination in the growing layer. The decomposition pathway of $\left(\mathrm{C}_{4} \mathrm{H}_{9}\right) \mathrm{AsH}_{2}$ has been studied in detail [20], [26], [27]. This compound appears to decompose through the homogenous fissure of the tertiary butyl radical, forming $\mathrm{AsH}_{x}$. This in situ generation of an AsH bearing species allows for the growth of very high purity $\mathrm{GaAs}$. The decomposition temperature of $\left(\mathrm{C}_{4} \mathrm{H}_{9}\right) \mathrm{AsH}_{2}$ is also lower than that of $\mathrm{AsH}_{3}$, resulting in the use of reduced gas phase concentrations of the compounds and allowing lower growth temperatures [26], [27].

The use of $\left(\mathrm{C}_{4} \mathrm{H}_{9}\right) \mathrm{AsH}_{2}$ and $\mathrm{C}_{2} \mathrm{H}_{5} \mathrm{AsH}_{2}$ as arsine substitutes has gained increasing acceptance in the field based on safety considerations. The direct substitution of these compounds for $\mathrm{AsH}_{3}$ can lead to changes in other important reactions occurring in the gas phase and on the surface. The doping efficiency of $\mathrm{SiH}_{4}$ and $\mathrm{Si}_{2} \mathrm{H}_{6}$ varies with the choice of As precursor. The Si incorporation in GaAs, in the case of $\mathrm{Si}_{2} \mathrm{H}_{6}$, exhibits no dependence on the growth temperature or relative ratio of $\mathrm{AsH}_{3} / \mathrm{Si}_{2} \mathrm{H}_{6}$ in the gas phase [28]. The $\mathrm{Si}$ incorporation from $\mathrm{SiH}_{4}, \mathrm{Si}_{2} \mathrm{H}_{6}$ [29], and $\mathrm{Si}_{2}\left(\mathrm{CH}_{3}\right)_{6}[30]$ increases at a given growth temperature with the replacement of $\mathrm{AsH}_{3}$ by $\left(\mathrm{C}_{4} \mathrm{H}_{9}\right) \mathrm{AsH}_{2}$. This increase and subsequent dependence of the $\mathrm{Si}$ incorporation on the relative ratio of $\left(\mathrm{C}_{4} \mathrm{H}_{9}\right) \mathrm{AsH}_{2} / \mathrm{Si}_{2} \mathrm{H}_{6}$ have been rationalized in terms of the radical attack of the $\mathrm{Si}_{2} \mathrm{H}_{6}$ doping source by the tertiary butyl radical, generated by the decompostion of the $\left(\mathrm{C}_{4} \mathrm{H}_{9}\right) \mathrm{AsH}_{2}$ [29]. This mechanism has yet to be verified and indicates the potential complexities of the gas phase and surface reactions.

In practical terms, the controlled doping of GaAs and related materials is particularly crucial for charge control devices. The local dependence of the doping efficiency over the wafer on the gas phase concentration of $\left(\mathrm{C}_{4} \mathrm{H}_{9}\right) \mathrm{AsH}_{2}$ increases the degree of control of the growth process required in order to obtain uniform growth and electrical characteristics. The control over the doping uniformity in the growth of digital device structures, when using these alternative As compounds, has not been addressed in the published literature. This issue stands as a significant hurdle for the acceptance of these compounds in the development of digital device applications. Other impurities also exhibit a strong dependence on the choice of $\mathrm{AsH}_{3}$ as an As precursor. The incorporation of oxygen into $\mathrm{Al}_{x} \mathrm{Ga}_{1-x}$ As from trace impurities in the process gases and from contamination of the metal-organic sources by oxygen-bearing compounds such as alkoxides, i.e. $\left(\mathrm{CH}_{3}\right)_{2} \mathrm{AlOCH}_{3}$, is strongly affected by the relative ratio of $\mathrm{AsH}_{3} /\left(\mathrm{CH}_{3}\right)_{2} \mathrm{AlOCH}_{3}$ in the gas stream [4]. The development of high luminescence efficiency $\mathrm{Al}_{x} \mathrm{Ga}_{1-x} \mathrm{As}$ for use in light emitter application is strongly dependent on the incorporation of oxygen into the films. The efficacy of $\left(\mathrm{C}_{4} \mathrm{H}_{9}\right) \mathrm{AsH}_{2}$ or $\mathrm{C}_{2} \mathrm{H}_{5} \mathrm{AsH}_{2}$ in removing oxygen from the growth front has yet to be determined experimentally and represents the next level of challenge required in the development of new sources. The development of these new sources must be within the context of the end device application resulting from the precursor use. The utility of these new sources may become very device specific, since each class of device is sensitive to a different set of uniformity and purity criteria.

The development of new group III sources has been slow compared with the pace of research into As and $P$ alternatives. The group III sources have been largely limited to the class of compounds $M R_{3-x} R_{x}^{\prime}$, where $R$ and $R^{\prime}$ are $\mathrm{H}, \mathrm{CH}_{3}, \mathrm{C}_{2} \mathrm{H}_{5}, \mathrm{C}_{3} \mathrm{H}_{7}$, or perhaps a halogen such as $\mathrm{Cl}$. There have been two main motivations for the development of these new precursors: 1) the need to reduce the unintentional carbon incorporation [31]-[33], originating from the metal-organic compound, and 2) the reduction in the reactivity of these compounds toward oxygen [34]. The first motivation arises in the development of charge control devices, where the unintentional carbon acts to compensate the intentional donors, thus changing the device characteristics. Carbon incorporation therefore leads to additional control problems in the formation of these device structures. 
Early work on the carbon incorporation led to several heuristic models describing the mechanism by which carbon is removed from the growth front. The most studied systems have been the $\left(\mathrm{CH}_{3}\right)_{3} \mathrm{Ga}$ and $\mathrm{AsH}_{3}$ based growth of GaAs. As mentioned above, the $\mathrm{AsH}_{3}$ is known to scavenge carbon-bearing methyl radicals with the resultant formation of $\mathrm{CH}_{4}$. The exact mechanism of this hydrogen transfer reaction is still a matter being discussed in the literature [24]. Several surface science techniques and methodologies have been brought to bear on this problem in connection with the use of these compounds in the atomic layer epitaxy (ALE) of GaAs and the growth of GaAs using MOMBE [35]. In both these cases, surface reactions involving the decomposition of the $\left(\mathrm{CH}_{3}\right)_{3} \mathrm{Ga}$ are important in the growth and impurity incorporation. These studies have revealed that the surface chemistry is dependent on the surface reconstruction of the GaAs surface [36]-[39]. Gas phase reactions within conventional MOVPE systems are an added complication to the ALE process. Additionally, the gas phase decomposition has also been studied in a variety of experimental arrangements [40]-[43]. These gas phase pyrolysis studies have indicated that decomposition of $\left(\mathrm{CH}_{3}\right)_{3} \mathrm{Ga}$ does occur under normal MOVPE growth conditions. This gas phase decomposition leads to the formation of $\mathrm{GaCH}_{3}$ and other fragments in the gas phase [44]. It is then these fragments which interact with the growth surface, adding a complication in the application of surface study results to conventional growth situations. The surface-based studies have been instrumental in pointing to the complexities of the decomposition pathways, which are often overlooked by the scientists and engineers in the field.

Experimental studies on GaAs growth using $\left(\mathrm{CH}_{3}\right)_{3} \mathrm{Ga}$ and $\mathrm{AsH}_{3}$ have elucidated key reactions important for the growth of high-purity GaAs. The methyl group originating from the metal-organic reacts with the hydrogen from the $\mathrm{AsH}_{3}$, removing most of the carbon from the growth system as $\mathrm{CH}_{4}$ [24]. The actual reaction pathway for the remaining carbon leading to its incorporation is still unknown. Whatever the pathway, the reaction leading to carbon incorporation is a minor pathway indeed. The typical carbon levels in MOVPE-based GaAs are less than $10^{16} \mathrm{~cm}^{-3}$, or less than a ppm. A probable route to carbon incorporation would be the formation of the reactive carbene, $\mathrm{CH}_{2}$, which would form two bonds to the growing surface, ensuring the incorporation of carbon into the growing layer [45], [46]. The formation of this carbene can occur through the radical attack of $\mathrm{CH}_{3}$ radicals on the gas phase $\left(\mathrm{CH}_{3}\right)_{3} \mathrm{Ga}$ molecules or surface resident $\mathrm{CH}_{3}$ groups. The methyl radical would extract a hydrogen atom from the methyl group, forming $\mathrm{CH}_{4}$ and $\mathrm{Ga}-\mathrm{CH}_{2}$ (surface). Support for this model has recently been obtained from infrared measurements of the GaAs surface which revealed the steady-state concentration of $\mathrm{CH}_{2}$ on the $\mathrm{GaAs}$ surface under growthlike conditions [47].

In order to eliminate the incorporation of carbon, either the carbon-based ligands should be removed from the precursor or a more facile route chosen for the decom- position. The replacement of the methyl groups by ethyl ligands, resulting in the precursor $\left(\mathrm{C}_{2} \mathrm{H}_{5}\right)_{3} \mathrm{Ga}$, can lead to very substantial decreases in the carbon incorporated into the growing $\mathrm{GaAs}$. The $\left(\mathrm{C}_{2} \mathrm{H}_{5}\right)_{3} \mathrm{Ga}$ decomposes through sequential $\beta$-hydride elimination reactions, such as

$$
\left(\mathrm{C}_{2} \mathrm{H}_{5}\right)_{3} \mathrm{Ga} \rightarrow\left(\mathrm{C}_{2} \mathrm{H}_{5}\right)_{2} \mathrm{GaH}+\mathrm{C}_{2} \mathrm{H}_{4} .
$$

This reaction results in the formation of $\mathrm{C}_{2} \mathrm{H}_{4}$, which has been shown to be inert within the MOVPE growth environment under most growth conditions [25]. The unimolecular decomposition of $\left(\mathrm{C}_{2} \mathrm{H}_{5}\right)_{3} \mathrm{Ga}$ does not require $\mathrm{AsH}_{3}$ to cleanly remove the carbon from the growth ambient. Additionally, the $\mathrm{Ga}-\mathrm{C}_{2} \mathrm{H}_{5}$ bond is weaker than the $\mathrm{Ga}-\mathrm{CH}_{3}$ bond, resulting in a lower temperature, highly facile decomposition reaction. While the carbon incorporation is reduced, the growth uniformity often is degraded when using $\left(\mathrm{C}_{2} \mathrm{H}_{5}\right)_{3} \mathrm{Ga}$ or $\left(\mathrm{C}_{2} \mathrm{H}_{5}\right)_{3} \mathrm{Al}$ because of the lower decomposition temperature and the subsequent premature decomposition of the compound prior to the growth front [48]. This uniformity problem is strongly affected by the reactor design.

The alternative route to reduced carbon incorporation would be the elimination of all carbon-bearing species from the growth reactor. The development of trimethyl amine alane, an adduct compound $\left(\mathrm{CH}_{3}\right)_{3} \mathrm{~N}: \mathrm{AlH}_{3}$, represents an attempt at a carbon-free growth chemistry [33], [49]-[51]. The amine group serves to stabilize the alane while preserving sufficient volatility. The analogous compound containing $\mathrm{Ga}$ has been also been synthesized and used in preliminary studies of GaAs growth [52]. The alane decomposes cleanly to $\mathrm{Al}$ metal at low temperatures. The low decomposition temperature of the alane-amine adduct is well suited to the ultra-high-vacuum-based MOMBE growth system, where prepyrolysis of the compound does not occur [51].

The use of this compound in the conventional MOVPE growth system does include several additional complications. The low pyrolysis temperature could lead to a thickness uniformity problem, as in the case of $\left(\mathrm{C}_{2} \mathrm{H}_{5}\right)_{3} \mathrm{Ga}$. The low carbon incorporation afforded by the alane compounds would not be necessary in many applications, such as solid-state lasers, where there is a device insensitivity to the level of carbon found with the use of $\left(\mathrm{CH}_{3}\right)_{3} \mathrm{Al}$. The growth of $\mathrm{Al}_{x} \mathrm{Ga}_{1-x} \mathrm{As}$ is complicated when using the alane since the carbon incorporation is affected by the choice of the Ga precursor [53]. Gas phase ligand exchange between $\left(\mathrm{CH}_{3}\right)_{3} \mathrm{Ga}$ and the $\mathrm{AlH}_{3}$ leads to the gas phase formation of mixed ligand species such as $\mathrm{CH}_{3} \mathrm{AlH}_{2}$. This gas phase formation process subsequently results in the incorporation of carbon, similar to that found with $\left(\mathrm{CH}_{3}\right)_{3} \mathrm{Al}$. The use of $\left(\mathrm{C}_{2} \mathrm{H}_{5}\right)_{3} \mathrm{Ga}$ together with the trimethyl amine alane also results in ligand exchange, but the resulting $\mathrm{C}_{2} \mathrm{H}_{5} \mathrm{AlH}_{2}$ compound can undergo the same $\beta$-elimination reaction described for the $\left(\mathrm{C}_{2} \mathrm{H}_{5}\right)_{3} \mathrm{Ga}$ based growth. A comparison of the PL spectra obtained from the combined use of methyl- and ethyl-based precursors is shown in Fig. 2. The alane compound, when used with $\left(\mathrm{C}_{2} \mathrm{H}_{5}\right)_{3} \mathrm{Ga}$, produces a 


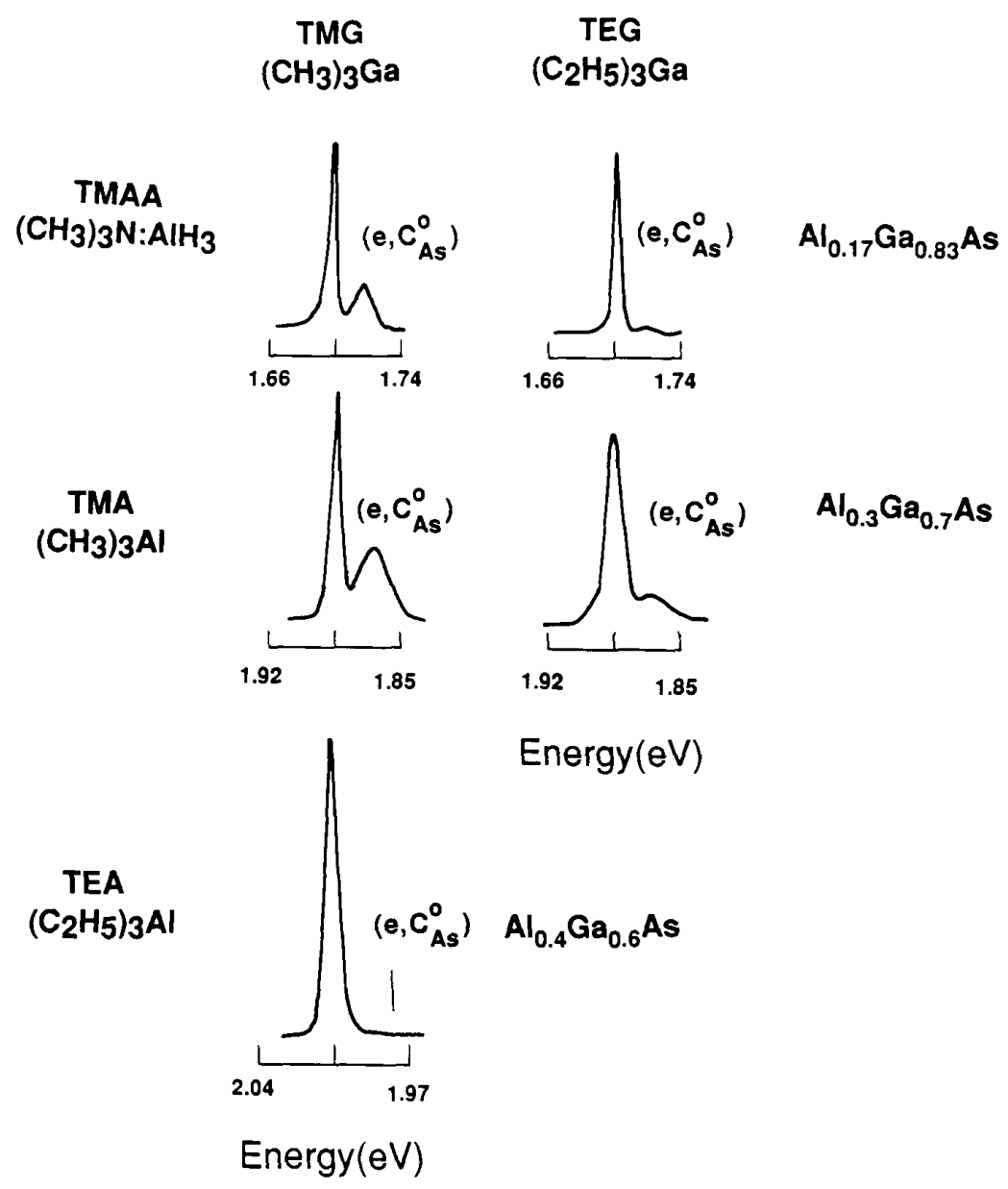

Fig. 2 The photoluminescence spectra taken from $\mathrm{Al}_{x} \mathrm{Ga}_{1-x}$ As samples indicate a sharp reduction in carbon content with the choice of growth precursor [48], [53]. The use of $\left(\mathrm{CH}_{3}\right)_{3} \mathrm{~N}: \mathrm{AlH}_{3}$ with $\left(\mathrm{C}_{2} \mathrm{H}_{5}\right)_{3} \mathrm{Ga}$ yields a low carbon content $\mathrm{Al}_{x} \mathrm{Ga}_{1-x} \mathrm{As}$ film.

low carbon level, as in the case of the combined use of $\left(\mathrm{C}_{2} \mathrm{H}_{5}\right)_{3} \mathrm{Al} /\left(\mathrm{C}_{2} \mathrm{H}_{5}\right)_{3} \mathrm{Ga}$.

\section{Directions in Growth Chemistry}

The research into the interaction between the growth chemistry and the reactor design is proceeding at a steady pace. The driving force for the development of new precursors has always been the production of "device-quality" materials. As the MOVPE technique matures and assumes a production role, the commercial focus on precursor development is directed toward improvements in the purity and the consistency of many of the existing compounds. New dopant and main group precursors are principally being developed in academic institutions. The development of a single source precursor for the growth of GaAs and other binary compounds is one such active area [54]-[56]. These compounds would be used in the low-temperature growth of $\mathrm{GaAs}$, where an additional vapor pressure of As may not be required. The initial efforts in this area are promising.
The formation of a new single source precursor which has sufficient vapor pressure and appropriate reaction pathways will require however a substantial amount of additional research and development effort.

A desirable goal for the MOVPE community is the development of a process analogous to the low-pressure chemical vapor deposition of polysilicon. A polysilicon reactor is a simple hot-wall or furnace tube reactor typically loaded with many (usually in excess of 50) vertically stacked Si wafers [57]. Polysilicon reactors are characterized by a high degree of thickness uniformity, which is controlled by the surface-reaction-limited decomposition of $\mathrm{SiH}_{4}$, which leads naturally to the establishment of a uniform growth in a multiwafer batch process. The polysilicon growth reactor has been extended to the deposition of epitaxial Si [58]. The analogous extension of a very low pressure multiwafer technology, as developed in the case of Si growth, to the epitaxial growth of GaAs and related compounds would be highly desirable. Such a technology would allow for the 
uniform growth and doping of many wafers within a batch run of the reactor. The uniformity is dictated by the surface reaction rate limited growth and doping behavior. The single source precursors, which exhibit such a growth rate dependence, may eventually be suitable for this application.

\section{NEW MATERIALS}

The application of MOVPE to new materials systems has always been an active area of research. There has been substantial progress in the areas of III-V, II-VI, and infrared detector materials. MOVPE has been extremely successful in the development of high-efficiency solar cells, photocathodes, and laser diodes. The extension of these successes to other device application areas will follow the further development of MOVPE in other materials systems. The following subsections will highlight progress in each of these classes of materials as grown by MOVPE.

\section{A. III-V Materials for Light Emission and High-Speed Electronic Devices}

The growth of visible light emitter structures in the red and orange wavelengths has focused on the $\left(\mathrm{Al}_{x} \mathrm{Ga}_{1-x}\right)_{0.52} \mathrm{In}_{0.48} \mathrm{P} / \mathrm{GaAs}$ lattice matched system. There are several attractive features of this combination of materials from both a device and a growth perspective. The $\left(\mathrm{Al}_{x} \mathrm{Ga}_{1-x}\right)_{0.52} \mathrm{In}_{0.48} \mathrm{P}$ system is lattice-matched to $\mathrm{GaAs}$ substrates and can span the direct bandgap range beyond $2.2 \mathrm{eV}$. The growth of these materials offers new challenges to the MOVPE field. There have been many successful demonstrations of heterostructure lasers in this materials system already [59], [60].

The materials challenges are generally associated with the presence of $\mathrm{Al}$ in the epitaxial layer. As with all Al-based materials, $\left(\mathrm{Al}_{x} \mathrm{Ga}_{1-x}\right)_{0.52} \mathrm{In}_{0.48} \mathrm{P}$ is sensitive to water and oxygen in the growth ambient. The incorporation of oxygen is a technological difficulty in the growth of these materials and is being resolved through the use of added precautions in the reactor design, to exclude oxygen and water from the growth environment, as well as an optimization of the growth conditions. The growth conditions for $\left(\mathrm{Al}_{x} \mathrm{Ga}_{1-x}\right)_{0.52} \mathrm{In}_{0.48} \mathrm{P}$ are more restrictive than the As-based materials. High growth temperatures, for example, are used in the MOVPE technique to facilitate the removal of oxygen from the growth front. Lower growth temperatures must be used here, however, compared with $\mathrm{Al}_{x} \mathrm{Ga}_{1 x}$ As growth due to the high volatility of phosphorus over the growing surface. The optimal growth temperature is therefore a compromise between these two materials demands: low oxygen incorporation and the need for high phosphorus over-pressures.

The growth of $\mathrm{Ga}_{0.50} \mathrm{In}_{0.50}$ P does not have these complicating features attributable to the presence of $\mathrm{Al}$. The interface between $\mathrm{Ga}_{0.50} \mathrm{In}_{0.50} \mathrm{P}$ and $\mathrm{GaAs}$ has been reported to be extremely good as a result with very low interface recombination velocities being reported [61]. It should be noted that low interface recombination velocities have also been recently reported in the case of the $\mathrm{Al}_{x} \mathrm{Ga}_{1-x} \mathrm{As} / \mathrm{GaAs}$ interface indicating that proper growth conditions and procedures can be found to reduce these contamination related effects [62]. A novel feature in the growth of alloy semiconductors, particularly $\operatorname{In}_{0.5} \mathrm{Ga}_{0.5} \mathrm{P}$ as well as $\left(\mathrm{Al}_{x} \mathrm{Ga}_{1-x}\right)_{0.52} \mathrm{In}_{0.48} \mathrm{P}$ is the appearance of ordering on the cation sublattice. The alloy ordering was first observed in the $\mathrm{Al}_{x} \mathrm{Ga}_{1-x} \mathrm{As}$ [63] alloy system and has since been seen in $\mathrm{In}_{x} \mathrm{Ga}_{1-x}$ As [64], $\mathrm{Ga}_{x} \mathrm{In}_{1-x} \mathrm{P}$ [65], $\mathrm{GaAs}_{x} \mathrm{Sb}_{1-x}$ [66], and other systems. Alloy ordering in the $\mathrm{Ga}_{x} \mathrm{In}_{1-x} \mathrm{P}$ system is characterized by the segregation of $\mathrm{Ga}$ and $\mathrm{In}$ to alternate $<111>$ planes [65]. This local ordering forms a natural monolayer superlattice structure, with the perfection of this ordering dependent on the growth conditions, i.e., growth temperature, V/III ratio, and the substrate crystallographic orientation [67]. The ordered structure was predicted to be the thermodynamically favored structure for many of these materials system including the $\mathrm{Ga}_{x} \mathrm{In}_{1-x} \mathrm{P}$ system [68], [69].

The appearance of the ordering and the specific orientation of the monolayer superlattice appear to be controlled by a surface process, as shown in Fig. 3 [70], with the exact nature of this ordering process still a matter of discussion. In a practical sense, the optical and electronic properties of the alloy are profoundly influenced by ordering induced changes in the fundamental direct bandgap. In the case of $\mathrm{Ga}_{0.5} \mathrm{In}_{0.5} \mathrm{P}$, a variation in the direct bandgap of up to -180 $\mathrm{meV}$ has been observed [67]. This variation in bandgap translates directly into the lasing or emission wavelength of the laser or LED. This ordering phenomena, while of great fundamental interest, therefore results in an added control problem in the growth of these materials.

The controlled doping of these visible light emitting materials also appears to offer new difficulties in the synthesis of device structures. The increased depth of the acceptor energy level with $\mathrm{Al}$ composition leads to decreased activation of the incorporated impurities. There appears to be additional compensation mechanisms operating in these materials, as is common in many widebandgap materials. High doping levels are required in laser structures in order to achieve low series resistance in the cladding regions. Both $\mathrm{Mg}$ and $\mathrm{Zn}$ have been extensively studied in this application [71], [72]. The higher growth temperatures desired for the growth of high $\mathrm{Al}$ content $\left(\mathrm{Al}_{x} \mathrm{Ga}_{1-x}\right)_{0.52} \operatorname{In}_{0.48} \mathrm{P}$ lead to rapidly decreasing incorporation of both $\mathrm{Mg}$ and $\mathrm{Zn}$ due to their high elemental vapor pressures. The doping and compensation in wide gap materials is an area which now appears to be a controlling factor in the application of these materials to many device structures.

The growth of longer wavelength lattice-matched materials has usually been limited to the $\mathrm{Al}_{x} \mathrm{Ga}_{1-x} \mathrm{As} / \mathrm{GaAs}$ and $\mathrm{In}_{x} \mathrm{Ga}_{1-x} \mathrm{P}_{y} \mathrm{As}_{1-y} / \mathrm{InP}$ materials systems. The access to wavelengths between these two alloy systems has recently been studied through the growth of strained layer laser structures [73], [74]. In particular, strained layer growth of laser materials within the $\mathrm{InGa}_{1-x} \mathrm{As}_{\mathrm{Al}} / \mathrm{Al}_{x} \mathrm{Ga}_{1-x} \mathrm{As} / \mathrm{GaAs}$ system has been the focus of many recent studies [74], [75]. The $\operatorname{In}_{x} \mathrm{Ga}_{1-x}$ As active region is pseudomorphically 


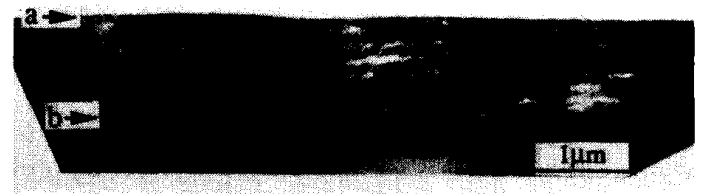

(a)

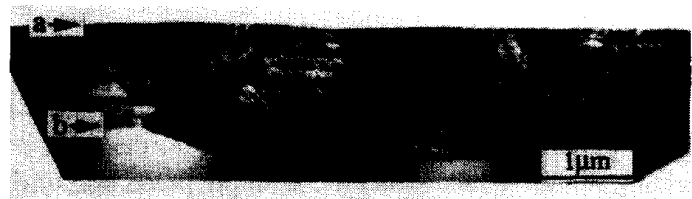

(b)

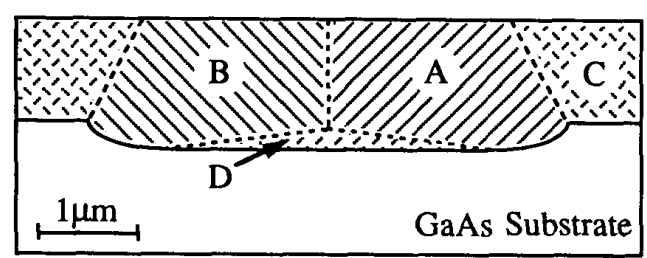

(c)

Fig. 3 The growth of $\operatorname{In}_{x} \mathrm{Ga}_{1-x} \mathrm{P}$ on patterned surfaces indicates the importance of surface processes, in this case surface steps, on the formation of the ordered structure [70]. The $1 / 2\langle 111\rangle$ formation of the transmission electron micrograph from either (a) the $1 / 2\langle\overline{1} 11\rangle$ or (b) or $1 / 2\langle 1 \overline{1} 1\rangle$ superstructure diffraction peaks selectively highlights one of the ordering variants. Only one varian of the ordered structure is apparent on each side of the patterned groove, indicating the influence of surface step motion on the formation of the ordered materials [70]. The letter "a" indicates the top surface, and " $b$ " the original growth interface. In (c) "A" and " $B$ " denote very large $[1 / 2\langle\overline{1} 11\rangle$ and $1 / 2\langle 1 \overline{1} 1\rangle]$ domains while " $C$ " and " $D$ " denote areas where small domains of the two variants coexist.

grown on the GaAs substrate. The use of thin quantum well structures not only allows device formation within this previously inaccessible wavelength region but also overlaps part of the wavelength region accessed by the $\mathrm{In}_{x} \mathrm{Ga}_{1-x} \mathrm{P}_{y} \mathrm{As}_{1-y}$ materials. The strained layer structures offer advantages in MOVPE growth. In particular, there are additional control requirements over the composition of the layer associated with exceeding the critical layer thickness for dislocation generation. The lifting of the valance band degeneracy under biaxial strain in these structures leads to a reduction in the threshold current density for lasing due to the reduction in the hole effective mass [76]. The reliability and long-term stability of these strained layer lasers appear to be excellent despite the presence of large internal strains [77].

\section{B. II-VI Visible Light Emitters}

The standard As and P-based semiconductors cannot be used in the formation of shorter wavelength light emitters in the green and blue regions. The technological interest in developing new shorter wavelength sources for optical recording, display, and communication purposes has spurred interest in the wider bandgap II-VI compounds. The binary compounds, $\mathrm{ZnSe}, \mathrm{ZnS}$, and $\mathrm{CdS}$, as well as the alloys of $\mathrm{ZnS}_{x} \mathrm{Se}_{1-x}$ and $\mathrm{Zn}_{x} \mathrm{Cd}_{1-x} \mathrm{Se}$, have received the greatest attention in this context. These wide gap materials offer the traditional benefits of a heterojunction growth technology: abrupt junctions, compositional control, and spatial control over the doping profile. The difficulties with this and other II-VI compounds lie in several areas: 1) mechanically weakness and softness compared with GaAs and Si substrates, easily resulting in mechanical damage through handling, 2) difficulty in obtaining highquality substrates, 3) controlled incorporation and electrical activation of dopants, and 4) formation of high-purity materials.

The MOVPE growth of the II-VI materials requires the use of low growth temperatures. This constraint arises from the need to minimize the anion and cation overpressure in the growth ambient required to stabilize the growth surface. These pressures, interrelated through the mass action considerations, increase exponentially with growth temperature. The vapor pressure of $\mathrm{Zn}$ over $\mathrm{Zn}$-stabilized $\mathrm{ZnSe}$, for example, is approximately equal to about 1 torr at $760 \mathrm{~K}$. Correspondingly, the vapor pressure of Se over the Se-stabilized $\mathrm{ZnSe}$ surface is about 1 torr at $640 \mathrm{~K}$. These high vapor pressures complicate the growth behavior as well as adding complexity to the reactor itself [78]

The choice of growth precursor has a central impact on the purity of the growing $\mathrm{ZnSe}$ layer. The efficient decomposition of the Se source compound is presently limiting the growth temperature. Several new Se compounds have been studied in order to determine both the decomposition pathways and the background impurity incorporation. Much of the work on $\mathrm{Se}$ compounds is related to the extensive research conducted on the growth of $\mathrm{CdTe} / \mathrm{Hg}_{x} \mathrm{Cd}_{1-x} \mathrm{Te}$ [79]. The Te precursor also limits the growth temperature in that case. A wide variety of Se precursors have been used which include $\mathrm{H}_{2} \mathrm{Se}$ [80], [81], $\left(\mathrm{CH}_{3}\right)_{2} \mathrm{Se}$ [82], $\left(\mathrm{C}_{2} \mathrm{H}_{5}\right)_{2} \mathrm{Se}$ [81], $\left(\mathrm{CH}_{3}\right)_{2} \mathrm{Se}_{2}$ [83], and $\left(\mathrm{C}_{2} \mathrm{H}_{5}\right)_{2} \mathrm{Se}_{2}$ and $\mathrm{CH}_{3} \mathrm{SeH}$ [84]. The growth temperature can be reduced within this series of Se precursors, with $\mathrm{H}_{2} \mathrm{Se}$ having the lowest characteristic growth temperature and $\left(\mathrm{C}_{2} \mathrm{H}_{5}\right)_{2}$ Se generally being used at the higher growth temperatures.

The choice of growth precursors for $\mathrm{ZnSe}$ is also affected by the possibility of gas phase parasitic reactions which can remove the $\mathrm{Zn}$ precursor from the gas phase. There is a strong gas phase reaction between $\left(\mathrm{CH}_{3}\right)_{2} \mathrm{Zn}$ and $\mathrm{H}_{2} \mathrm{Se}$, which results in the formation of a low vapor pressure adduct compound which precipitates onto the reactor walls, altering the gas phase composition. These parasitic reactions can be suppressed by reactor design [85] and through the choice of an alternative Se precursor. The use of organoselenium compounds results in the suppression of these gas phase reactions but at the expense of requiring higher growth temperatures. The use of the allyl compounds, while perhaps affording additional reductions in the growth temperature, has been shown to result in a high concentration of carbon in the $\mathrm{ZnSe}$ films [86]. So while $\mathrm{H}_{2} \mathrm{Se}$ can produce high-purity films at temperatures as low as $280^{\circ} \mathrm{C}$, the growth rate control and film uniformity are very poor. Recently, Wright, Jones, and coworkers [87], [88] have developed $\mathrm{Zn}$-adduct compounds, such 
as $\left(\mathrm{CH}_{3}\right)_{2} \mathrm{Zn}: \mathrm{N}\left(\mathrm{CH}_{3}\right)_{3}$, which eliminates the preliminary reaction between $\mathrm{H}_{2} \mathrm{Se}$ and the $\mathrm{Zn}$ precursor. The addition of pyridine $\left(\mathrm{C}_{5} \mathrm{H}_{5} \mathrm{~N}\right)$ to the gas stream has also been recently shown to reduce the gas phase reactions between $\left(\mathrm{CH}_{3}\right)_{2} \mathrm{Zn}$ and $\mathrm{H}_{2} \mathrm{Se}$ [89]. These chemical approaches to designing a growth procedure appear to be most promising for eliminating the deleterious effects present in conventional growth.

Despite the challenges presented in the crystal growth of $\mathrm{ZnSe}$ and related materials, there have been several recent milestones achieved in the growth of electroluminescent device structures. The growth of pulsed current $77 \mathrm{~K}$ $\mathrm{ZnSe} / \mathrm{CdZnSe}$ quantum well laser has been demonstrated by MBE [90]. The continued effort in the MOVPE-based growth of these structures will hopefully provide an alternative process for the formation of these lasers.

\section{NEW Growth Structures}

MOVPE has recently been successful in producing a variety of new structures which fall into two classes: low dimensional structures and chip-level materials integration. The push to higher performance laser structures, such as quantum dot and line lasers, with improved temperature stability and lower current thresholds, has been studied through the growth on patterned substrates and selective epitaxial techniques. MOVPE is particularly useful in these types of patterned growth. The development of new growth chemistries and a deepening knowledge of the surface transport phenomena underlying the epitaxial growth process have allowed for a new degree of control over the lateral growth behavior of epitaxial structures. Epitaxial processes have already excelled at the fine degree of control over the compositional and electrical properties of materials in the vertical direction. Quantum wells and superlattices have resulted and have been incorporated into optical and electronic device structures. The formation of one- and zero-dimensional structures (quantum lines and dots) has been accomplished through the implementation of a variety of new growth methodologies. These methodologies can be divided into growth on patterned substrates and patterned growth on planar substrates.

Growth on patterned substrates has focused on the formation of distributed Bragg reflector structures [91] and the growth of quantum lines [92]. The formation of Bragg reflectors is typically accomplished by the patterning of an existing epitaxial structure through conventional photolithographic patterning of a holographic image. The surface relief is imposed on the structure through the controlled etching of the wafer. The structure is then prepared for a subsequent epitaxial growth step. This is a particularly demanding growth procedure due to several complicating features: the presence of surface contamination resulting from the previous growth step, the surface mass transport of mobile species, and the difficulties associated with the heteroepitaxial growth on the preprocessed surface [93], [94]. The lateral mass transport of material during the pregrowth heating and annealing is most problematic for

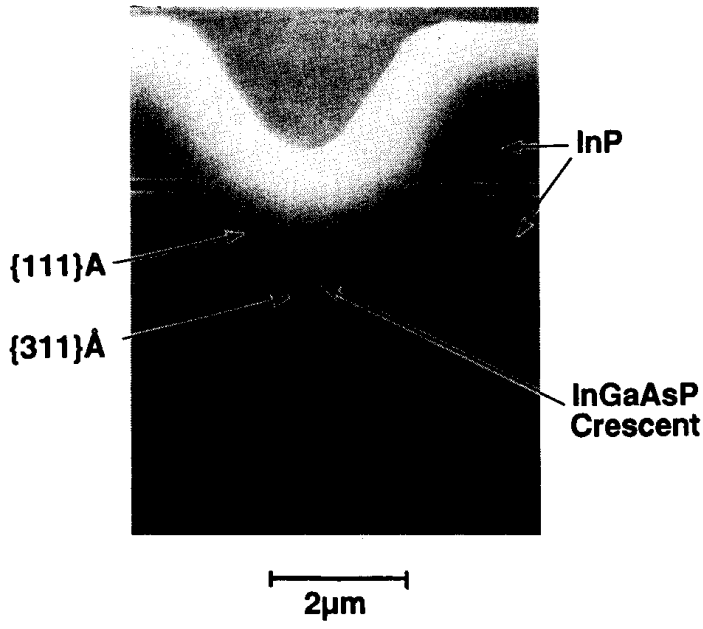

Fig. 4. Growth on patterned substrates provides a means by which quantum wires or line structures can be fabricated either in an array or for a single wire. The high surface mobility realized on the $\langle\overline{1} 11\rangle$ type exposed planes. The lasing would take place within the $\mathrm{In}_{x} \mathrm{Ga}_{1-x} \mathrm{P}_{y} \mathrm{As}_{1-y}$ selective growth regions [93].

In-based compounds, presumably due to the low enthalpy of formation of InP and $\operatorname{InGa}_{1-x}$ As [95]. Mass transport can be used to advantage in several structures whereby InP can be transported from regions adjacent to an $\operatorname{InGa}_{1-x}$ As active region, resulting in the surface passivation of this interface.

The growth on patterned substrates has also been used to form quantum line structures. In this case, an existing epitaxial structure is patterned and etched to reveal particular crystallographic planes. Several wet chemical etching procedures exist for the $\operatorname{In}_{x} \mathrm{Ga}_{1-x} \mathrm{P}_{y} \mathrm{As}_{1-y}$ and $\mathrm{Al}_{x} \mathrm{Ga}_{1-x} \mathrm{As}$ alloy systems which exhibit a very slow etch rate for the $\langle 111\rangle$ and $\langle 110\rangle$ families of planes. The resulting "V grooves" serve as substrates for the subsequent growth. Growth of lattice matched $\mathrm{InGa}_{1-x}$ As on patterned InP substrates results in the preferential growth of the $\operatorname{InGa}_{1-x}$ As or $\operatorname{In}_{x} \mathrm{Ga}_{1-x} \mathrm{P}_{y} \mathrm{As}_{1-y}$ at the vertex of the groove [96]. The high surface mobility of the growth reactant on the exposed $<111>$ faces allows lateral mass transport into the groove. The cessation of growth after a short time results in the deposition of a thin layer, about $10 \mathrm{~nm}$ in thickness and $30 \mathrm{~nm}$ in width. The subsequent growth of an InP cladding layer results in the formation of a quantum line embedded in a double heterostructure configuration, as seen in Fig. 4 [93].

The study of the surface mobility and transport as a function of growth orientation and growth temperature can be used to alter the growth habit of the structure during the epitaxial growth process, as illustrated in Fig. 5 [97]. This technique, referred to as temperature programmed growth, can lead to the formation of buried heterostructure lasers which do not rely on the use of externally patterned substrates. Laser arrays and buried heterostructure lasers have been demonstrated using this technique [96]. The formation of vertical cavity lasers has been a recent 


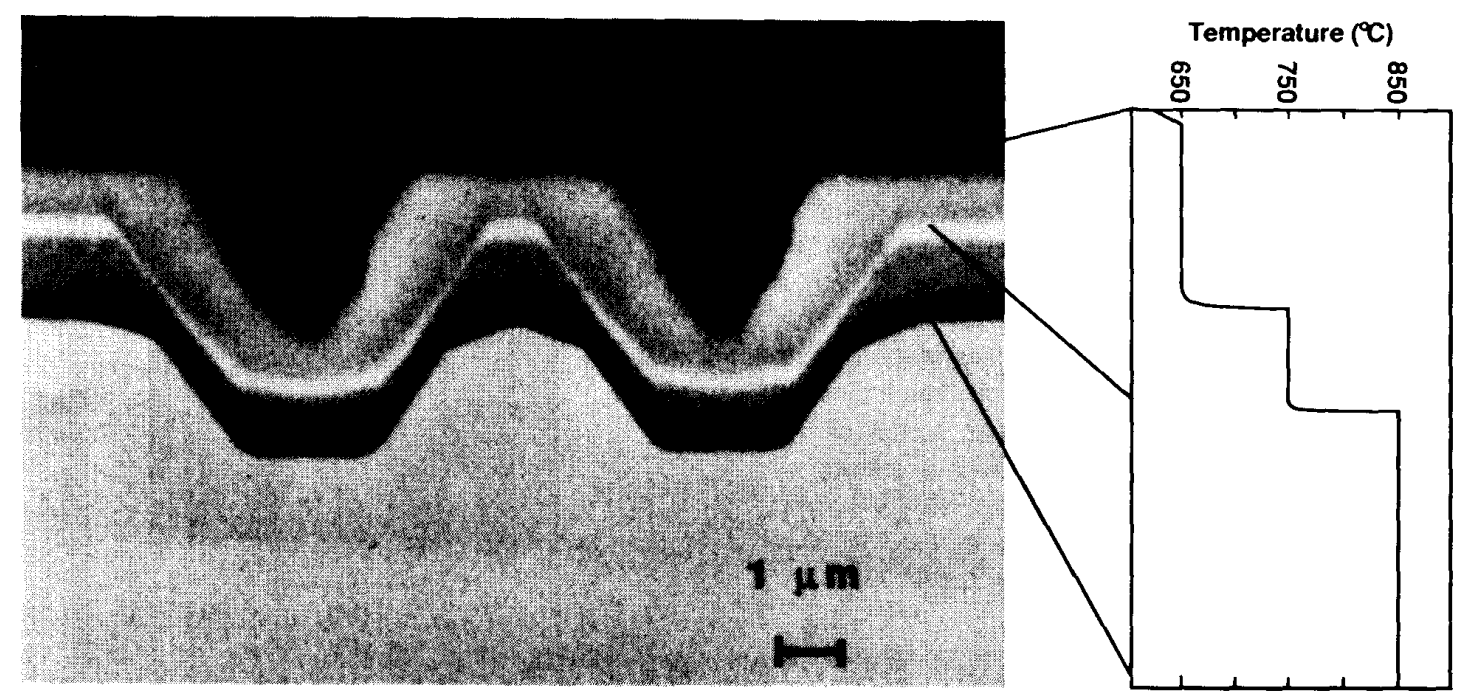

Fig. 5 The control of the growth habit over patterned substrates can be achieved through changes in the growth temperature. The relative growth rates on exposed substrate surface planes can be tuned from a high to a very low ratio. The change in growth temperature allows for the growth of epitaxial materials preferentially on either the exposed (100) surface, at $850^{\circ} \mathrm{C}$ and $750^{\circ} \mathrm{C}$, or nonpreferentially at the lower growth temperature of $650^{\circ} \mathrm{C}$. Temperature programmed growth has been used successfully to form buried heterostructure lasers possessing a low threshold current density [117].

active area of MOVPE development. The formation of these vertical cavity structures requires the growth of a multilayer stack which has a high degree of control over the individual layer thickness and composition as well as the total multilayer stack properties. These properties must be controlled in order to achieve the high reflectivity and phase matching required at the lasing wavelength. There have been successful demonstrations of the MOVPE growth of these materials in the $\mathrm{GaAs} / \mathrm{Al}_{x} \mathrm{Ga}_{1-x}$ As [98].

Selective epitaxy is a general area of activity which allows for the lateral definition of a growing structure as well as the integration of a variety of materials into an existing wafer. The chip-level integration of differing materials structures, and hence devices, is a path to the formation of monolithic structures previously built in a hybrid form. The integration of light detectors, optimized for a specific spectral range, with analog and digital circuits can be used to reduce the size and cost of communication equipment. Selective area growth is being used in these applications to produce localized regions of growth and device formation.

Selective epitaxy has been used to refer to several different growth procedures. The growth on patterned substrates is a form of selective epitaxy since only the local regions within the "V groove" are sites for epitaxial growth. A more general materials technology for selective epitaxy would entail growth only over specific areas of the substrate surface. Two approaches have been used to accomplish this end. Localized heating or photolysis through an externally imposed light source, most commonly a laser, has been used to produce localized regions of growth [99], [100]. The lateral resolution of these regions is a function of the wavelength of light, the substrate thermal behavior, and the duration of exposure. At present, regions as small as several microns have been produced and utilized in the demonstration of this localized growth technique. These features are somewhat large for the growth of the smaller device structures. Alternatively, a masking layer can be used to prevent epitaxial growth, resulting in the deposition of polycrystalline materials [101], or growth conditions can be chosen to eliminate deposition on the masked regions entirely [102]. The latter technique obviously does not require the subsequent removal of polycrystalline deposition from the masked field regions.

The choice of growth chemistry and conditions is central to the selective epitaxial growth afforded by MOVPE. The use of a conventional growth precursor, such as $\left(\mathrm{CH}_{3}\right)_{3} \mathrm{Ga}$ and $\left(\mathrm{CH}_{3}\right)_{3} \mathrm{Al}$, can lead to the gas phase transport of these growth nutrients from around a mask opening to the exposed wafer surface. The local growth rate is then a function of the pattern geometry, reactor temperature, and pressure. The combined effects of gas phase and surface transport can be cleverly used in many structures, forming, for example, tapered waveguides [103]. Alternatively, the growth chemistry can be modified through the use of halogenated growth precursors such as $\left(\mathrm{C}_{2} \mathrm{H}_{5}\right)_{2} \mathrm{GaCl}$ [104]. The gas phase decomposition of this compound to $\mathrm{GaCl}$ leads to the complete absence of deposits on the masked field regions, as shown in Fig. 6 [103]. As a result, the selective area deposition is limited by lithographic constraints in the system. This latter technique has been successfully employed in the formation of source and drain contact regions in submicron field effect transistor structures (FET's) [105]. The presence of a small amount 

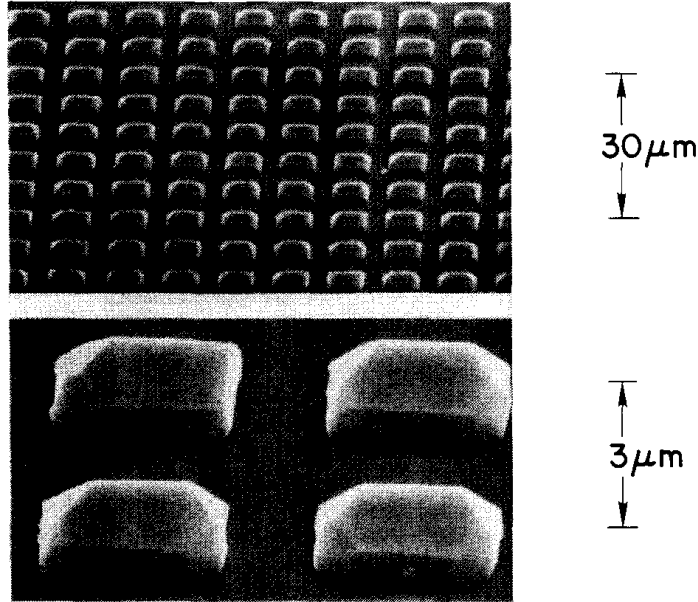

Fig. 6. The selective area growth of $\mathrm{Al}_{x} \mathrm{Ga}_{1-x} \mathrm{As}$ and GaAs-based heterostructures can be accomplished using an alternative growth precursors such as $\left(\mathrm{C}_{2} \mathrm{H}_{5}\right)_{2} \mathrm{GaCl}$ and $\left(\mathrm{C}_{2} \mathrm{H}_{5}\right)_{2} \mathrm{AlCl}$. Highly uniform growth of selectively grown regions in arrays or in isolated regions can be achieved. When combined with nonselective-based growth, the masking material can be embedded into the growth structure. The definition of the selectively grown structures is limited by lithographic constraints in the initial pattern definition [103].

of $\mathrm{HCl}$ in the gas phase during the initial stages of the epitaxial growth leads to the removal of surface impurities present after the pregrowth processing. This added benefit of the halogenated growth precursors is crucial in applications where current transport across the regrown interface is important. The interfacial contact resistance of the $\left(\mathrm{C}_{2} \mathrm{H}_{5}\right)_{2} \mathrm{GaCl}$-based regrown interfaces has been extremely low compared with the conventional $\mathrm{Au}-\mathrm{Ge}-\mathrm{Ni}$ based ohmic contact metallurgy and is quite suitable for this application.

\section{New Growth TeChnologies}

The thickness, doping uniformity, and reproducibility achievable in conventional MOVPE have often been considered insufficient for many device applications. Such limitations on the MOVPE growth product are attributable, in part, to the open-loop nature of the control process in MOVPE and to the reactor design. Research addressing these limitations to the widespread use of MOVPE in the compound semiconductor industry is currently active. The application of fluid-flow calculations to the realistic design of reactors, initial work on in situ monitoring and control, and the development of new growth procedures in specialized reactors (e.g. ALE reactors) will be discussed.

\section{System Monitors}

One approach to the improvement of the growth uniformity and reproducibility is through the redesign of the conventional MOVPE reactor. Recently, redesigns have been based on the application of fluid-flow calculations to the realistic flow and geometry of reactors. This work is an extension of the fundamental studies described in a previous section, and novel reactor designs have resulted which are currently being evaluated [106], [107].

An alternative and very promising field of research is the development of new monitoring techniques for real-time control of a working MOVPE system. Currently, the development of a new MOVPE process, as well as the routine exercise of a developed process, requires a constant application of a regimen of growth-characterization-recalibrationgrowth. This regimen is wasteful of time and resources. The major drawback of this mode of development is the inability to characterize the growing layer during formation. Thus, the use of in situ monitors, which could effectively control those parameters affecting the growth rate and composition, would be desirable. The initial work on in situ monitoring and control has focused on the use of optical probes of the growing surface. The simplest embodiment of an optical probe is the use of optical reflectivity during the growth of heterostructures [108]. The change in index of refraction at the heterointerface can lead to oscillations in the reflected light signal from the sample surface. Single wavelength reflectance during growth can be used to determine the "real-time" growth rate once the optical constants of the epitaxial material are known. This technique has been instrumental in the development of novel multilayer structures, such as vertical cavity lasers [109], where not only a high degree of control is required over both the individual layer thicknesses but also the replication of the bilayer structure throughout the many periods. This technique is similar to the recent use of the oscillations in the pyrometer signals during the temperature measurements of the $\mathrm{MBE}$ substrate [110].

An associated technique is the use of spectroscopic ellipsometry to determine the growing layer composition and thickness [111]. This technique, as well as the laser reflectance, has been integrated directly into the control elements which determine the gas phase composition within the reactor, thereby providing real-time control over the epitaxial growth. Other control monitors have included the direct measurement of the gas phase composition of an individual component through the use of sound velocity measurements. The development of more sophisticated control monitors and the application of process control methodologies, so common in other industrial processes, will be an essential step in the development of MOVPE as an industrial growth technique

In situ monitors and controls will be required to routinely achieve the level of reproducibility required in new, more demanding device structures, particularly in the area of microwave and electronic device structures. A notable absence from these studies, however, has been the attempt to monitor and control the doping incorporation into a growing layer through in situ monitors. This problem is indeed less tractable due to the nonlinear dependence of the incorporation of the dopant on growth temperature, pressure, and other gas phase constituents. The major difficulty in monitoring the gas phase concentration of a particular dopant species is the typically very low gas phase 


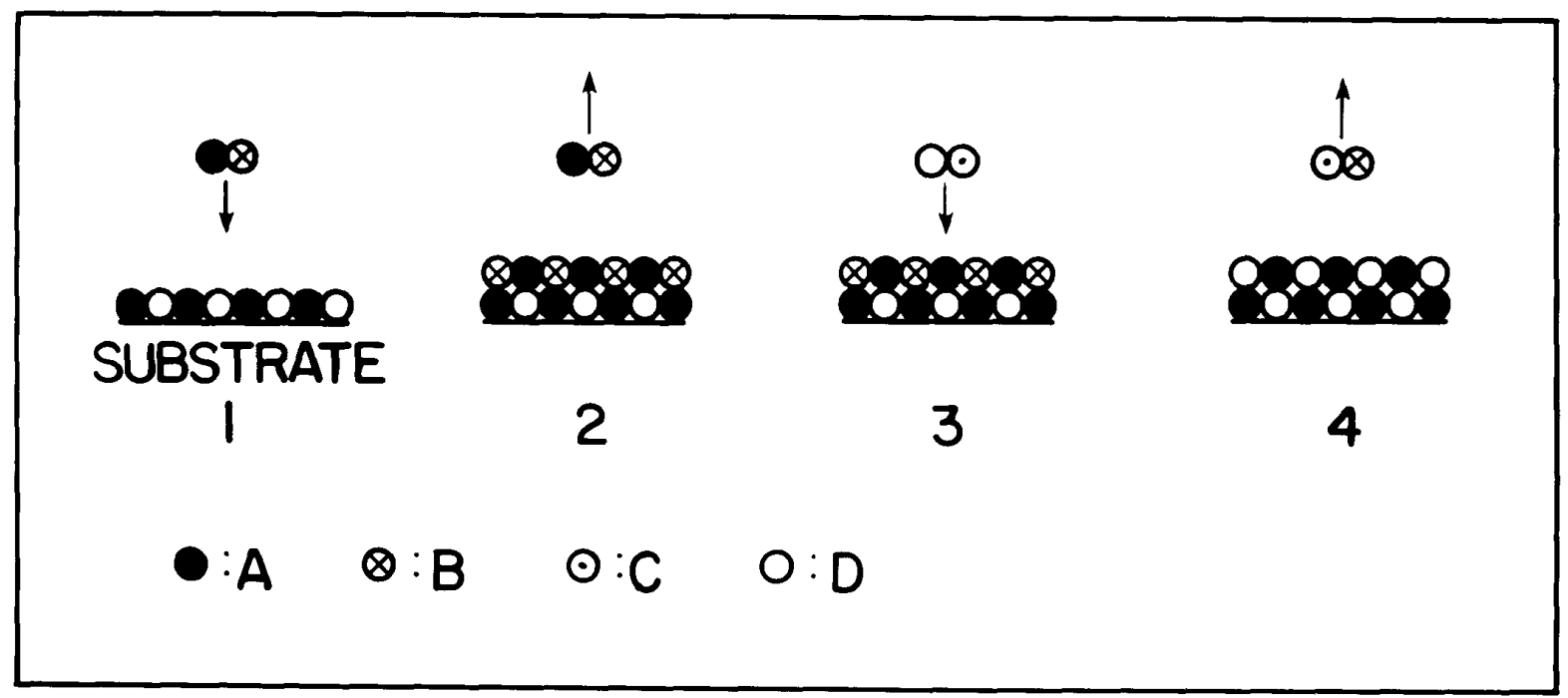

Fig. 7. The atomic layer epitaxy process is schematically shown. In step 1, the substrate is exposed to a precursor, $A B$. The continued exposure of the substrate, 2 , results effectively in a single adsorbed monolayer. This adsorbate covered substrate is then exposed to the other precursor in step 3. The decomposition of the second precursor and the removal of any reaction by-product result in the formation of a single uniform and complete layer of the deposited material. In the case of GaAs ALE, the initial $A B$ precursor is $\mathrm{Ga}\left(\mathrm{CH}_{3}\right)_{x}$ and the $C D$ precursor is $A s \mathrm{H}_{x}$

concentration of precursor within the reactor. A typical mole fraction of $\mathrm{Si}_{2} \mathrm{H}_{6}$ within a MOVPE reactor, during GaAs or InP growth, is on the order of $10^{-7}$ to $10-8$, making detection extremely difficult. The real-time control of such minor constituents is difficult to achieve in principle and awaits further research efforts.

A major effort within the MOVPE community which has attempted to address the issues of uniformity and reproducibility is ALE [112]-[114]. The concept of ALE is quite simple; however, in practice the underlying chemistry of ALE has been shown to be quite complex. In ALE, the growth reactants are sequentially delivered to the growth surface. For example, a single growth cycle would consist of a growth surface first being exposed to $\left(\mathrm{CH}_{3}\right)_{3} \mathrm{Ga}$ and then, after purging the reactor, being exposed to $\mathrm{AsH}_{3}$. The reactor temperature, gas phase composition, and reactant exposure time can be chosen such that the sequence results in the formation of a single and complete monolayer of either $\mathrm{Ga}$ or As on the surface, as schematically shown in Fig. 7. The attractive feature of ALE is that the deposition of Ga or As can be made self-limiting under limited growth conditions with only one layer, not multiple layers, of reactant being deposited. The completion of each cycle of gas exposures results in the uniform deposition of a single monolayer of GaAs. This growth mode results in a process where uniformity of growth is a natural consequence of the self-limiting growth behavior and the growth thickness is determined solely by the number of growth cycles. ALE is a low-temperature growth technique when compared with conventional MOVPE processes. This low-temperature behavior has the typical benefits, such as low dopant diffusion, as well as some of the limitations, notably enhanced impurity incorporation and low growth rates. Growth in a kinetically limited regime does offer the possibility of extending the number of wafers within the batch-mode processing behavior of the CVD. The development of a truly kinetically limited process would allow for an analogous reactor development to the present polysilicon growth reactor, which is probably the most successful reactor design in the semiconductor industry.

The most studied ALE material system is the growth of GaAs from $\left(\mathrm{CH}_{3}\right)_{3} \mathrm{Ga}$ and $\mathrm{AsH}_{3}$. Research into the ALE of GaAs has progressed on two fronts: investigations of the underlying chemistry of ALE and the development of ALE-based materials and devices. The application of new surface sensitive optical spectroscopies, such as reflectance difference spectroscopy (RDS), [115] surface photo-adsorption [116], traditional surface science techniques, primarily temperature programmed desorption, $\mathrm{X}$ ray and ultraviolet photoemission, and mass spectroscopy, has led to several models describing the detailed ALE growth process. The rapid developments in this field and the range of experimental data developed from these studies should soon lead to a conclusive mechanistic model of the ALE process which can hopefully be extended to chemically related growth systems.

The major limitation in the application of the ALE process has been the impurity content of the resulting epitaxial layers. The low growth temperatures and perhaps the sequential growth nature of the process, wherein all gas phase processes between the Ga and As growth constituents are suppressed, contribute to the elevated levels of carbon $\left(>10^{17} \mathrm{~cm}^{-3}\right.$ ) measured in most ALE films. Recent studies have found that an appropriate growth process window 
exists in temperature and exposure sequence wherein low carbon level materials $\left(<10^{15} \mathrm{~cm}^{-3}\right)$ can be produced in GaAs [117]. These improved materials have been used in the demonstration of several device structures, most notably solid-state lasers and FET's. Structures formed by the ALE process should exhibit performance comparable to their conventionally grown counterparts and should benefit from the improved yield. A primary device area which could substantially benefit from the application of a suitable ALE technique comprises FET's and other charge control devices. The threshold voltage as well as several of the primary device characteristics relies on control over the spatial distribution of the impurity, i.e., the integrated thickness-doping product. The ALE technology has focused so far on achieving a high degree of control over the growth uniformity. The development of a controlled doping technology with a comparable degree of control over the dopant incorporation is still required within the context of a self-limited growth process.

\section{SUMMARY}

The field of MOVPE has progressed over the last decade since its initial widespread application to optical device structures. The major accomplishments of the technique include the establishment of a routine growth technique for the formation of long-wavelength lasers and other demanding optical devices structures. The slow development of MOVPE in the field of electronic device structures is related to our limited understanding of the underlying issues controlling impurity incorporation and the primary chemical and reactor related factors controlling the over-the-wafer and run-to-run uniformity and reproducibility of the growth process. The relationship between the growth chemistry and the structure and electronic properties underlies the continued development of the MOVPE technique as it is applied to the formation of advanced heterostructure devices. The chemical diversity of source materials and the adaptive nature of the growth system will continue to place MOVPE at the forefront of the development of new materials.

\section{ACKNOWLEDGMENT}

The author wishes to thank R. Bhat, P. D. Dapkus, G. B. Stringfellow, and $\mathrm{H}$. Moffat for providing materials used in the figures. J. Redwing is also acknowledged for her careful reading of the manuscript. The author would also like to acknowledge his previous coworkers from the IBM T. J. Watson Research Center, namely R. Potemski, M. A. Tischler, and T. N. Theis, for their help in many aspects of the work described here.

\section{REFERENCES}

[1] H. Manasevit, "The use of metalorganics in the preparation of semiconductor materials: Growth on insulating substrates," $J$. Crystal Growth, vol. 13/14, pp. 306-314, 1972; "A survey of the heteroepitaxial growth of semiconductor films on insulating substrates," vol. 22, 125-148, 1974.
[2] G. B. Stringfellow, Organometallic Vapor Phase Epitaxy. San Diego, CA: Academic Press, 1989.

[3] N. Holonyak, Jr., R. M. Kolbas, R. D. Dupuis, and P. D. Dapkus, "Room-temperature continuous operation of photopumped MOCVD $\mathrm{Al}_{x} \mathrm{Ga}_{1-x}$ As-GaAs- $\mathrm{Al}_{x} \mathrm{Ga}_{1-x}$ As quantum well lasers," Appl. Phys. Lett., vol. 33, pp. 73-75, 1978; R D. Dupuis and P. D. Dapkus, "Preparation and properties of $\mathrm{Ga}_{x} \mathrm{Al}_{1-x} \mathrm{As}-\mathrm{GaAs}$ heterostructure lasers grown by metalorganic chemical vapor deposition," IEEE J. Quantum Electron., vol. 15 , pp. $128-135,1979$; P. D. Dapkus, "Metal-organic chemical vapor deposition," Ann. Rev. Mat. Sci., vol. 12, pp. 243-269, 1988.

[4] T. F. Kuech, R. Potemski, F. Cardone, and G. Scilla, "Quantitative oxygen measurements in OMVPE $\mathrm{Al}_{x} \mathrm{Ga}_{1-x}$ As grown by methyl precursors," J. Electron. Mater., vol. 21, pp. 341-346, 1992.

[5] T. F. Kuech, and K. F. Jensen, "OMVPE of compound semiconductors," in Thin Film Processes II, J. L. Vossen and W Kern, Eds. Orlando, FL: Academic Press, 1991, pp. 369-442.

[6] A. Robertson, Jr., T. H. Chiu, W. T. Tsang, and J. E. Cunningham, "A model for the surface chemical kinetics of GaAs deposition in chemical beam epitaxy," J. Appl. Phys., vol. 64, pp. 877-887, 1988.

[7] H. Tanaka et al. "Multi-wafer growth of HEMT LSI quality $\mathrm{AlGaAs} / \mathrm{GaAs}$ heterostructures by MOCVD," Japan J. Appl. Phys., vol. 26, pp. L1456-L1458, 1987

[8] J. Komeno et al. "Recent progress in MOVPE for HEMT LSIs," J. Crystal Growth, vol. 105, pp. 30-34, 1990.

[9] K. F. Jensen, "Chemical vapor deposition," in Microelectronics Processing, D. W. Hess and K. F. Jensen, Eds. Washington, DC: American Chemical Society, 1989, ch.5, pp. 199-263.

[10] D. W. Kisker, D. R. McKenna, and K. F. Jensen, "Limitation to the OMVPE growth of $\mathrm{Hg}$ compounds due to hydrodynamic effects," Mater. Letters, vol. 6, pp. 123-128, 1988.

[11] M. Tirtiwidjojo and R. Pollard, "Elementary processes and ratelimiting factors in MOVPE growth," J. Crystal Growth, vol. 93 , pp. 108-114, 1988.

[12] D. I. Fotiadiis, A. M. Kremer, D. R. McKenna, and K. F. Jensen, "Complex flow phenomena in vertical MOCVD reactors: Effects on deposition uniformity and interface abruptness," J. Crystal Growth, vol. 85, pp. 154-164, 1987; G. Evans and R. Grief, "Effects of boundary conditions on the flow and heat transfer in a rotating disk chemical vapor deposition reactor," Num. Heat Transfer, vol. 12, pp. 243-252, 1987; E. P. Visser, C. R. Kleijn, C. A. M. Govers, C. J. Hoogerdoorn, and L. J. Giling, "Return flows in horizontal MOCVD reactors studied with the use of $\mathrm{TiO}_{2}$ particle injection and numerical calculations," J. Crystal Growth, vol. 94, pp. 929-946, 1989; R. J. Field, "Simulations of two-dimensional recirculating flow effects in horizontaal MOVPE," J. Crystal Growth, vol. 97, pp. 739-760, 1989; J. Quanzzani, C.-C. Chiu, and F. Rosenberger, "On the 2D modeling of horizontal CVD reactors and its limitations," J. Crystal Growth, vol. 91, pp. 497-508, 1988.

[13] H. K. Moffat and K. F. Jensen, "Three-dimensional flow effects in silicon CVD in horizontal teactors," J. Electrochem. Soc., vol. 135, pp. 459-471, 1988; E. O. Einset and K. F. Jensen, "Models of growth rate and compositional uniformity of OMVPE InGaAs," presented at the Fifth Biennial Workshop on Organometallic Vapor Phase Epitaxy, Panama City, FL, Apr. 14-17, 1991.

[14] J. Quazzani and F. Rosenberger, "Three-dimensional modeling of horizontal chemical vapor deposition I. MOCVD at atmospheric pressure," J. Crystal Growth, vol. 100, pp. 545-576, 1990.

[15] H. K. Moffat, T. F. Kuech, K. F. Jensen, and P. J. Wang, "Gas phase and surface reactions in Si-doping of GaAs by silanes", J. Crystal Growth, vol. 93, pp. 594-601, 1988.

[16] K. F. Jensen, D. I. Fotiadis, and T. J. Mountziaris, "Models and mechanisms of III-V compound semiconductor growth by MOVPE," in III-V Heterostructures for Electronic/Photonic Devices, C. W. Tu, V. D. Mattera, and A. C. Gossard, Eds., Proc. Mat. Res. Soc. (Pittsburgh, PA), vol. 145, 1989, pp. $107-119$.

[17] C. H. Chen, C. A. Larsen, G. B. Stringfellow, D. W. Brown, and A. J. Robertson, "MOVPE growth of InP using isobutylphosphine and tertiary-butylphosphine," J. Crystal Growth, vol. 77,

pp. 11-18, 1986 .
[18] C. H. Chen, C. A. Larsen, and G. B. Stringfellow, "Use of 
tertiarybutylarsine for GaAs growth," Appl. Phys. Lett., vol. 50, pp. 218-220, 1987

[19] G. Haacke, S. P. Watkins, and H. Burkhard, "Contol of residual impurity incorporation in tertiarybutylarsine-grown GaAs," $J$ Crystal Growth, vol. 107, pp. 342-347, 1991

[20] R. M. Lum and J. K. Klingert, "Alternative group V precursors for MOVPE,” J. Crystal Growth, vol. 107, pp. 290-296, 1991.

[21] G. B. Stringfellow, "Non-hyidride group V sources for OMVPE," J. Electron. Mater., vol. 17, pp. 327-335, 1988

[22] G. T. Muhr, D. A. Bohling, T. R. Omstead, S. Brandon, and K. F. Jensen, "Recent advances in the development of arsine substitutes for use in metal-organic vapor phase epitaxy of GaAs," Chemtronics, vol. 4, pp. 26-30, 1989.

[23] D. M. Speckman and J. P. Wendt, "Vapor deposition of highpurity GaAs epilayers using monoethylarsine," Appl. Phys. Lett., vol. 56, pp. 1134-1136, 1990.

[24] T. F. Kuech and E. Veuhoff, "Mechanism of carbon incorporation in MOCVD GaAs," $J$. Crystal Growth, vol. 68, pp. $148-156,1984$

[25] T. F. Kuech, G. Scilla, and F. Cardone, "The influence of hydrocarbons in MOVPE GaAs growth: Improved detection of carbon by secondary ion mass spectroscopy," J. Crystal Growth, vol. 93, pp. 550-556, 1988.

[26] C. A. Larsen, N. I. Buchan, S. H. Li, and G. B. Stringfellow, "GaAs growth using tertiarybutylarsine and trimethylgallium," J. Crystal Growth, vol. 93, pp. 15-19, 1988.

[27] P. W. Lee, T. R. Omstead, D. R. McKenna, and K. F. Jensen, "In-situ mass spectroscopy studies of the decomposition of organometallic arsenic compounds in the presence of $\left(\mathrm{CH}_{3}\right)_{3} \mathrm{Ga}$ and $\left(\mathrm{C}_{2} \mathrm{H}_{5}\right)_{3} \mathrm{Ga}$," J. Crystal Growth, vol. 93, pp. 134-142, 1988.

[28] E. Veuhoff, T. F. Kuech, and B. S. Meyerson, "A study of silicon incorporation in GaAs MOCVD layers," J. Electrochem. Soc., vol. 132, pp. 1958-1961, 1985

[29] T. Kikkawa, H. Tanaka, and J. Komeno, "Difference in Sidoping efficiency in tertiarybutylarsine, monoethylarsine and arsine for GaAs and AlGaAs grown by MOVPE," J. Electron. Mater., vol. 21, pp. 305-315, 1992.

[30] R. L. Lum, J. L. Klingert, and F. A. Stevie, "Controlled carbon doping of GaAs films grown with tertiarybutylarsine," J. Appl. Phys., vol. 67, pp. 6507-6512, 1990.

[31] N. Koyabashi and N. Fukui, "Improved 2DEG mobility in selectively doped $\mathrm{GaAs} / \mathrm{N}-\mathrm{AlGaAs}$ grown by MOCVD using triethyl organometallic compounds," Electron. Lett., vol. 20, pp. $887-888,1984$

[32] T. F. Kuech, E. Veuhoff, T. S. Kuan, V. Deline, and R. Potemski, "The influence of growth chemistry on the MOVPE growth of GaAs and $\mathrm{Al}_{x} \mathrm{Ga}_{1-x}$ As layers and heterostructures," J. Crystal Growth, vol. 77, pp. 257-271, 1986.

[33] A. C. Jones and S. A. Rushworth, "Growth of low carbon content $\mathrm{Al}_{x} \mathrm{Ga}_{1-x}$ As by reduced pressure MOVPE using trimethylamine alane," J. Crystal Growth, vol. 107, p. 350 1991.

[34] L. Pohl, "Physical properties of non-pyrophoric group III precursors for MOVPE," J. Crystal Growth, vol. 107, pp. 309-313, 1991.

[35] References in Atomic Layer Growth and Processing, T. F. Kuech, P. D. Dapkus, and Y. Aoyagi, Eds., Proc. Mat. Res. Soc. (Pittsburgh, PA), vol. 222, 1991.

[36] M. L. Yu, N. I. Buchan, R. Souda, and T. F. Kuech, "Surface chemistry and mechanism of atomic layer growth of GaAs," in Atomic Layer Growth and Processing, T. F. Kuech, P. D Dapkus, and Y. Aoyagi, Eds., Proc. Mat. Res. Soc. (Pittsburgh, PA), vol. 222, 1991, pp. 3-14.

[37] J. R. Crieghton and B. A. Banse, "The surface chemistry of gaas atomic layer epitaxy", in Atomic Layer Growth and Processing, T. F. Kuech, P. D. Dapkus, and Y. Aoyagi, Eds., Proc. Mat. Res. Soc. (Pittsburgh, PA), vol. 222, 1991, pp. 15-24.

[38] B. Y. Maa and P. D. Dapkus, "The mechanisms and kinetics of surface reactions of trimethylgallium on GaAs (001) surfaces and its relevance to atomic layer epitaxy" in Atomic Layer Growth and Processing, T. F. Kuech, P. D. Dapkus, and Y. Aoyagi, Eds., Proc. Mat. Res. Soc. (Pittsburgh, PA), vol. 222, 1991 , pp. $25-40$.

[39] D. E. Aspnes et al., "Real-time optical diagnostics for measuring and controlling epitaxial growth," in Atomic Layer Growth and Processing, T. F. Kuech, P. D. Dapkus, and Y. Aoyagi, Eds., Proc. Mat. Res. Soc. (Pittsburgh, PA), vol. 222, 1991, pp. 63-74.

[40] P. Lee, T. R. Omstead, D. R. McKenna, and K. F. Jensen, "In- situ mass spectroscopy and thermogravimetric studies of GaAs MOCVD gas phase and surface reactions," J. Crystal Growth, vol. 85 , pp. $165-174,1987$

[41] M. G. Jacko and S. J. W. Price, "The pyrolysis of trimethyl gallium," Can. J. Chem., vol. 41, pp. 1560-1567, 1963.

[42] S. P. DenBaars, B. Y. Maa, P. D. Dapkus, A. D. Danner, and H. C. Lee, "Homogeneous and heterogeneous thermal decomposition rates of trimethylgallium and arsine and their relevance to the growth of GaAs by MOCVD," J. Crystal Growth, vol. 77, pp. 188-193, 1986

[43] C. A. Larsen, N. I. Buchan, and G. B. Stringfellow, "Reaction mechanisms in the organometallic vapor phase epitaxial growth of GaAs," Appl. Phys. Lett., vol. 52, pp. 480-482, 1988.

[44] J. E. Butler, N. Bottka, R. S. Sillman, and D. K. Gaskill, "In-situ real-time diagnostics on OMVPE using IR-diode laser spectropscopy, J. Crystal Growth, vol. 77, pp. 163-171, 1986.

[45] N. I. Buchan, T. F. Kuech, G. Scilla, F. Cardone, and R. Potemski, "Carbon incorporation in metal-organic vapor phase epitaxy grown $\mathrm{GaAs}$ from $\mathrm{CH}_{x} \mathrm{I}_{4-x}, \mathrm{HI}$, and $\mathrm{I}_{2}, J$. Electron. Mater., vol. 19, pp. 277-281, 1990.

[46] K. F. Jensen, D. I. Fotiadis, and T. J. Mountziaris, "Detailed models of the MOVPE process", J. Crystal Growth, vol. 107, pp. 1-12, 1991

[47] A. V. Annapragada and K. F. Jensen, "In-situ FTIR and mass spectroscopy studies of surface chemistry of organometallic As-compounds," presented at the Fifth Biennial Workshop on Organometallic Vapor Phase Epitaxy, Panama City, FL, Apr. 14-17, 1991.

[48] T. F. Kuech, E. Veuhoff, T. S. Kuan, V. Deline, and R. Potemski, "The influence of growth chemistry on the MOVPE growth of $\mathrm{GaAs}$ and $\mathrm{Al}_{x} \mathrm{Ga}_{1-x}$ As layers and heterostrctures," J. Crystal Growth, vol. 77, pp. 257-271, 1986

[49] D. B. Beach, S. E. Blum, and F. K. LeGous, "Chemical vapor deposition of aluminum from trimethylamine-alane," J. Vac. Sci. Technol., vol. A7, pp. 3117-3118, 1989.

[50] W. L. Gladfelter, D. C. Boyd, and K. F. Jensen, "Trimethylamine comlexes of alane as precursors for the low-pressure chemical vapor deposition of aluminum," Chem. Mater, vol. 1, pp. 339-343, 1989.

[51] C. R. Abernathy, "Growth of high quality AlGaAs by metalorganic molecular beam epitaxy using trimethylamine allane," Appl.Phys. Lett., vol. 56, pp. 2654-2656, 1990.

[52] W. L. Gladfelter et al., "Trimethylamine gallane as a precursor to cubic gallium nitride and gallium arsenide. Metal hydride chemical vapor deposition," in Chemical Prespectives of Microelectronic Materials II, L. V. Interrante, K. F. Jensen, L. H. Dubois, and M. E. Gross, Proc. Mat. Res. Soc., vol. 204, 1991, pp. $83-94$.

[53] A. C. Jones, S. A. Rushworth, D. A. Bohling, and G. T Muhr, "Growth of $\mathrm{Al}_{x} \mathrm{Ga}_{1-x}$ As by reduced pressure MOVPE using trimethylamine allane," J. Crystal Growth, vol. 106, pp. $246-252,1990$.

[54] C. G. Pitts, K. T. Higa, and R. L. Wells, "Synthesis and crystal structure of tris(dimesitylarsino) gallane, a monomeric tricoordinate gallium-arsenic compound," Inorg. Chem., vol. 25, pp. 2483-2484, 1986.

[55] E. K. Byrne, L. Parkanyi, and K. H. Theopold, "Design of a monomeric arsinogallane and chemical conversion to gallium arsenide," Science, vol. 241, pp. 332-335, 1988.

[56] R. A. Jones, A. H. Cowley, and J..G. Ekerdt, "Single source precursors for III-V OMCVD growth and pyrolysis studies," in Chemical Prespectives of Microelectronic Materials II, L. V. Interrante, K. F. Jensen, L. H. Dubois, and M. E. Gross, Proc. Mat. Res. Soc., vol. 204, pp. 73-82, 1991.

[57] S. Middleman and A. Yeckel, "A model of the effects of diffusion and convection on the rate and uniformity of deposition in a CVD reactor," J. Electrochem. Soc, vol. 133, pp. 1951-1956, 1986.

[58] B. S. Meyerson, "Low temperature Si and Si:Ge epitaxy by ultrahigh-vacuum/chemical vapor deposition: Process fundamentals," IBM J. Res. Develop., vol. 34, pp. 806-815, 1990; also see B. S. Meyerson in this issue.

[59] K. Itaya, Y. Watanabe, M. Ishikawa, G. Hatakoshi, and Y. Uematsu, "High power operation of heterobarrier blocking structure InGaAlP visible light laser structure," Appl. Phys. Lett., vol. 56, pp. 1718-1719, 1990.

[60] F. A. Kish et al.,"Visible spectrum native-oxide coupled-stripe $\mathrm{In}_{0.5}\left(\mathrm{Al}_{x} \mathrm{Ga}_{1-x}\right)_{0.5} \mathrm{P}-\operatorname{In}_{0.5} \mathrm{Ga}_{0.5} \mathrm{P}$ quantum well heterostructure 
laser arrays," Appl. Phys. Lett., vol. 59, pp. 2883-2885, 1991

[61] J. M. Olson, R. K. Ahrenkiel, D. J. Dunlavy, B. Keyes, and A. E. Kibbler, "Ultra-low recombination velocity at $\mathrm{Ga}_{0.5} \mathrm{In}_{0.5} \mathrm{P}$," Appl. Phys. Lett., vol, 55, pp. 1208-1210, 1988.

[62] D. J. Wolford et al.,"Intrinsic recombination and interface characterization in "surface free" GaAs Structures," J. Vac. Sci. Technol., vol. B9, pp. 2369-2376, 1991; G. D. Gilliland, D. J. Wolford, T. F. Kuech, and J. A. Bradley, "Intrinsic, heterointerface excitonic states in $\mathrm{GaAs}(\mathrm{n}) / \mathrm{Al}_{0.3} \mathrm{Ga}_{0.7} \mathrm{As}(\mathrm{p})$ double heterostructures," J. Vac. Sci. Technol., vol. B9, pp. 2377-2383, 1991.

[63] T. S. Kuan, T. F. Kuech, W. I. Wang, and E. L. Wilkie, "Long range order in $\mathrm{Al}_{x} \mathrm{Ga}_{1-x} \mathrm{As}$," Phys. Rev. Lett., vol. 54, pp. 201-204, 1985.

[64] M. A. Shahid and S. Mahajan, "Long-range atomic order in $\mathrm{Ga}_{x} \mathbf{I n}_{1-x} \mathrm{As}_{y} \mathbf{P}_{1-y}$ epitaxial layers [ $(x, y)=(0.47,1)$, $(0.37,0.82),(0.34,0.71)$, and $(0.27,0.64)]$, , Phys. Rev., vol. B38, pp. $1344-1350,1988$

[65] A. Gomyo, T. Suzuki, and S. Iijima, "Observation of strong ordering in InGa ${ }_{1-\mathrm{x}} \mathrm{P}$ alloy semiconductors," Phys. Rev. Lett., vol. 60, pp. 2645-2648, 1988

[66] H. R. Jen, M. J. Jou, Y. T. Cherng, and G. B. Stringfellow, "The kinetic aspects of ordering in GaAs1 $-x \mathrm{Sb} x$ grown by organometallic vapor phase epitaxy," J. Crystal Growth, vol. 85 , pp. $175-181,1987$.

[67] A. Gomyo et al., "Studies of $\mathrm{Ga}_{x} \operatorname{In}_{1-x} \mathrm{P}$ layers grown by metalorganic vapor phase epitaxy; Effects of V/III ratio and growth temperature," J. Crystal Growth, vol. 77, pp. 367-373, 1986.

[68] G. P. Srivastava, J. L. Martins, and A. Zunger, "Atomic structure and ordering in semiconductor alloys," Phys. Rev., vol. B31, pp. 2561-2564, 1985.

[69] J. L. Martins and A. Zunger, "Stability of ordered bulk and epitaxial semiconductor alloys," Phys.Rev. Lett., vol. 56, pp. $1400-1403,1986$

[70] G. S. Chen and G. B. Stringfellow, "Effects of step motion on ordering in GaInP," Appl. Phys. Lett., vol. 59, pp. 324-326, 1991.

[71] Y. Ohba, Y. Nishikawa, C. Nozaki, H. Sugawara, and T. Nakanisi, "A study of p-type doping for AlGaInP grown by lowpressure MOCVD," J. Crystal Growth, vol. 93, pp. 613-617, 1988.

[72] P. Roentgen, W. Heuberger, G. L. Bona, and P. Unger, "MOVPE of AlGaInP/GaInP heterostructures for visible lasers," J. Crystal Growth, vol. 107, pp. 724-730, 1991

[73] W. D. Laidig, P. J. Caldwell, Y. F. Lin, and C. K. Peng, "Strained-layer quantum-well laser," Appl.Phys. Lett., vol. 44, pp. 653-655, 1984

[74] P. K. York et al., "Effect of confining layer aluminum composition on AlGaAs-GaAs-InGaAs strained-layer quantum well heterostructure lasers," Appl. Phys. Lett., vol. 57, pp. 843-845, 1990.

[75] D. Hall et al., "Broadband long wavelength operation $(9700 \AA>$ $\lambda>8700 \AA$ ) of $\mathrm{Al}_{y} \mathrm{Ga}_{1-y}$ As-GaAs-In $\mathrm{Ga}_{1-x}$ As quantum well heterostructure lasers in an external cavity," Appl.Phys. Lett. vol. 55, pp. 752-754, 1989.

[76] E. Yablonovich and E. O. Kane, "Band structure engineering of semiconductor lasers for optical communications," J. Lightwave Technol., vol. 6, pp. 1292-1299, 1988.

[77] K. J. Beernink et al., "Characterization of InGaAs-GaAs strained-layer lasers with quantum wells near the critical thickness," Appl. Phys. Lett. vol. 55, pp. 2167-2169, 1989.

[78] L. M. Smith and J. Thompson, "Metal organic chemical vapor deposition (MOCVD) of cadmium telluride, mercury telluride, and cadmium mercury telluride," Chemtronics, vol. 4, pp. 60-70, and references therein, 1989.

[79] H. M. Manasevit and W. I. Simpson, "The use of metalorganics in the preparation of semiconductor materials, II. II-VI compounds," J. Electrochem. Soc., vol. 118, pp. 644-647, 1971

[80] W. Stutius, "Organometallic vapor deposition of epitaxial $\mathrm{ZnSe}$ films on GaAs substrates," Appl. Phys. Lett., vol. 33, pp $656-658,1978$

[81] H. Mitsuhashi, I. Misuishi, and H. Kukimoto, "Growth kinetic in the MOVPE of $\mathrm{ZnSe}$ on GaAs using zinc and selenium alkyls," J. Crystal Growth, vol. 77, pp. 219-222, 1986.

[82] K. P. Gaipis, K. F. Jensen, J. E. Potts, and S. J. Pachuta "Investigation of carbon incorporation in $\mathrm{ZnSe}$ : Effects on morphology, electrical, and photoluminescence properties," $J$.
Electron. Mater., vol. 19, pp. 453-462, 1990

[83] S. Fujita T, Sakamoto, M. Isemura, and S. Fujita, "Use of methylselenol for organometallic vapor phase epitaxy of $\mathrm{ZnSe}$," J. Crystal Growth, vol. 87, pp. 581-584, 1988.

[84] K. P. Giapis, D.-C. Lu, D. I. Fotiadis, and K. F. Jensen, "Temperature variations in electrical and photoluminescence properties of $\mathrm{ZnSe}$ grown by MOCVD," J. Crystal Growth, vol. 104, pp. 291-296, 1990.

[85] S. Patnaik, K. F. Jensen, and K. P. Giapis, "MOVPE of ZnSe using organometallic allyl selenium precursors," J. Crystal Growth, vol. 107, pp. 390-395, 1991.

[86] P. J. Wright et al., "MOCVD layer growth of $\mathrm{ZnSe}$ and $\mathrm{ZnS} / \mathrm{ZnSe}$ multiple layers using nitrogen containing adducts of dimethylzinc," J. Crystal Growth, vol. 104, pp. 601-609, 1990.

[87] A. C. Jones, P. J. Wright, and B. Cockayne, "Precursors for II-VI semiconductors: Requirements and developments," $J$. Crystal Growth, vol. 107, pp. 297-308, 1991

[88] P. J. Wright, B. Cockayne, P. J. Parbrooke, P. E. Oliver, and A. C. Jones, "Control of prereaction in the metalorganic chemical vapor deposition of zinc-and cadmium-based chalcogenides," $J$. Crystal Growth, vol. 108, pp. 525-533, 1991.

[89] M. A. Haase, J. Qui, J. M. DePuydt, and H. Cheng, "Blue-green laser diodes," Appl. Phys. Lett., vol. 59, pp. 1272-1274, 1991.

[90] T. Ohata et al., "AlGaAs/GaAs distributed feedback laser diodes grown by MOCVD," J. Crystal Growth, vol. 77, pp. 637-642, 1986

[91] E. Kapon, S. Simhony, R. Bhat, and D. M. Hwang, "Single quantum wire semiconductor lasers," Appl.Phys. Lett., vol. 55, pp. 2715-2717, 1989 .

[92] T. Tanbun-Ek et al., "Reproducible growth of narrow linewidth multiple quantum well graded index separate confinement distributed feedback (MQW-GRIN-SCH-DFB) lasers by MOVPE," J. Crystal Growth, vol. 107, pp. 751-756, 1991.

[93] E. Colas et al., "Growth of GaAs quantum wire arrays by organometallic chemical vapor deposition on submicron gratings," Appl. Phys. Lett., vol. 57, pp. 914-916, 1990.

[94] T. R. Chen et al. "Study and application of the mass transport phenomenon in InP," J. Appl. Phys., vol. 54, pp. 2407-2412, 1983.

[95] R. Bhat et al., "Quantum wire lasers by OMCVD growth on non-planar substrates," J. Crystal Growth, vol. 107, pp. 716-723, 1991.

[96] K. M. Dzurko, E. P. Menu, C. A. Beyler, J. S. Osinski, and P. D. Dapkus, "Temperature engineered growth of lowthreshold quantum well lasers by metalorganic chemical vapor deposition," Appl.Phys. Lett., vol. 54, pp. 105-107, 1989.

[97] C. F. Schaus et al., "Transverse junction vertical-cavity surfaceemitting laser," Appl. Phys. Lett., vol. 58, pp. 1736-1739, 1991.

[98] N. H. Karam, H. Liu, I. Yoshida, B.-L. Jiang and S. M. Bedair "Low temperature selective epitaxy of III-V compounds by laser assisted chemical vapor deposition," J. Crystal Growth, vol. 93, pp. 254-258, 1988.

[99] O. Chen, J. A. Osinski, C. A. Beyler, and P. D. Dapkus, "Quantum well lasers with active region grown by laser-assisted atomic layer epitaxy," Appl.Phys. Lett., vol. 57, pp. 1437-1439, 1990.

100] S. H. Jones and K. M. Lau, "Selective area growth of high quality GaAs by OMCVD using native oxide masks," J. Electrochem. Soc., vol. 134, pp. 3149-3155, 1987.

[101] H. Heinecke et al., "Selective growth of GaAs in the MOMBE and MOCVD sytsems," J. Crystal Growth, vol. 77, pp. 303-309, 1986.

[102] E. Colas et al., "In-situ definition of semiconductor structures by selective area growth and etching," Appl.Phys. Lett., vol. 59, pp. 2019-2021, 1991.

[103] T. F. Kuech et al., "Selective epitaxy of GaAs, $\mathrm{Al}_{x} \mathrm{Ga}_{1-x} \mathrm{As}$, and $\mathrm{InGa}_{1-x}$ As," J. Crystal Growth, vol. 107, pp. 116-128, 1991.

[104] A. Palevski, P. Solomon, T. F. Kuech, and M. A. Tischler, "Regrown ohmic contacts to thin GaAs layers and two-dimensional electron gas," Appl. Phys. Lett., vol. 56, pp. 171-173, 1990.

[105] P. M. Frijlink, "A new versatile, large size MOVPE reactor," J. Crystal Growth, vol. 93, pp. 207-215, 1988.

[106] P. M. Frijlink, J. L. Nicolas, and P. Suchet, "Layer uniformity in a multi-wafer MOVPE reactor for III-V compounds," J. Crystal Growth, vol. 107, pp. 166-174, 1991

[107] L. E. Tarof, C. J. Miner, and A. J. Springthorpe, "Epitaxial layer thickness measurements by reflection spectroscopy," $J$. 
Electron. Mater., vol. 18, pp. 361-367, 1989

[108] J. L. Jewell, J. P. Harbison, A. Sherer, Y. H. Lee, and L. T. Florez, "Vertical cavity surface-emitting lasers: Design, growth, fabrication, characterization," IEEE J. Quantum Electron., vol. 27, pp. 1332-1346, 1991.

[109] A. J. Springthorpe and A. Majeed, "Epitaxial growth rate measurements during molecular beam epitaxy," J. Vac. Sci. Technol., vol. 8, pp. 266-270, 1990.

[110] W. E. Quinn, D. E. Aspnes, and S. Gregory, "Applications of spectroellipsometry to the growth of GaAs and AlGaAs by metalorganic molecular beam epitaxy," J. Crystal Growth, vol. 107 , pp. $1045-1046,1991$

[111] A. Usui, in this volume.

[112] T. Suntola, "Atomic layer epitaxy," Mater. Sci. Reports, vol. 4 , pp. 261-312, 1989.

[113] M. Ozeki, "Atomic layer epitaxy of III-V compounds using metalorganic and hydride sources," Mater. Sci. Reports, vol. 8, pp. 97-146, 1992.

[114] E. Colas et al., "In-situ monitoring of growth by reflectance difference spectroscopy," J. Crystal Growth, vol. 107, pp. 47-55, 1991 .

[115] N. Kobayashi and Y. Horikoshi, "Optical investigation on the growth process of GaAs during migration enhanced epitaxy", Japan J. Appl. Phys., vol. 28, pp. L1880-L1882, 1989.

[116] K. Mori, M. Yoshida, A. Usui, and H. Terao, "GaAs growth by atomic layer epitaxy using diethyl gallium chloride," Appl.Phys. Lett., vol. 52, pp. 27-29, 1988.

[117] K. M. Dzurko, E. P. Menu, C. A. Beyler, J. S. Osinski, and P. D. Dapkus, "Low threshold quantum well lasers grown by met- alorganic chemical vapor deposition on nonplanar substrates," IEEE J. Quantum Electron., vol. 25, pp. 1450-1458, 1989.

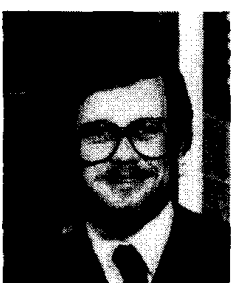

Thomas F. Kuech (Member, IEEE) was born in Milwaukee, WI, on September 9, 1954. He received the B.S. degree (1976) in physics from Marquette University in Milwaukee as well as an M.S. in materials science (1977). He received both an M.S. (1977) and a Ph.D. (1981) in applied physics from the California Institute of Technology.

He was a Research Staff Member at the IBM T. J. Watson Research Center from 1981 to 1990. While at IBM, he was manager of IIIV Epitaxial Growth group. He has been a member of the faculty of the Chemical Engineering Department at the University of Wisconsin in Madison since 1990. He has been involved in the study of the OMVPE growth process as well as its application to digital and optical device structures at both IBM and the University of Wisconsin. The relationship between the physics and chemistry of growth and the attainment of novel materials, structures, and device enhancements has been a main direction of this work. He has published in the fields of epitaxial growth, transport properties of Schottky barriers, ohmic contacts, and heteroepitaxial structures, nonstoichiometric ceramic oxides, and the solid-state properties of semiconductor materials. 